\title{
INVESTIGATING THE STATIC RESPONSE OF HYBRID FIBRE-METAL LAMINATE DOUBLERS LOADED IN TENSION
}

\author{
Sugiman $^{1}$, AD Crocombe ${ }^{1}$, KB Katnam ${ }^{2}$ \\ ${ }^{1}$ Division of Mechanical, Medical and Aerospace Engineering, Faculty of Engineering and \\ Physical Sciences, University of Surrey, Guildford, Surrey, GU2 7XH, UK. ${ }^{2}$ Composite \\ Research Centre, Kathleen Lonsdale Building, University of Limerick, Limerick City, \\ Ireland.
}

\begin{abstract}
Experimental and numerical studies have been undertaken on hybrid fibre-metal (aluminiumGlare) laminate (FML) doubler joints to investigate their static response under tension loading. The specimens either have the fibres parallel to the loading direction (spanwise) or perpendicular to the loading direction (chordwise). Inevitably sheets in these laminates butt together and these butts can affect the joint strength. The effect of the butt position was investigated. The spanwise specimen was found to have the highest strength followed by chordwise specimens without butts and finally chordwise specimens with butts. The most critical position for a butt was found to be adjacent to the doubler end. The ultimate strength for spanwise and chordwise specimens without butts was controlled by the failure in the Glare layer, however for specimens with butts, the butts control the ultimate strength. A progressive damage numerical analysis was undertaken using cohesive zone elements to model failure in the Glare and in the adhesive layers. This modelling was found to be in good agreement with the experiment data both in terms of the strength and the failure mechanisms.
\end{abstract}

Keywords: (A) Laminates (B) Strength (C) Numerical analysis

\footnotetext{
1 Intwodnotinn

*Corresponding author. Telp.: +44 1483689194

E-mail address: a.crocombe@ surrey.ac.uk
} 
Monolithic aluminium such as Al 2024-T3, has been widely used in aircraft structures over many years. However monolithic aluminium is prone to fatigue failure especially in (tensile) lower wing structures. In monolithic aluminium, once the surface crack has initiated this accelerates leading to the premature failure. This has been a concern to the aircraft industry for many years. Realising this problem, Schliekelmann [1] used laminated aluminium on the Fokker wing structure which improved the fatigue performance. Schijve $e t$ $a l$. [2] used aluminium laminates on a large wing joint and explored the fatigue properties of aluminium laminates. The finding was surprising, because the crack growth was extremely slow. The crack initiated in the outer layer and the other layers bridged the crack slowing down the crack propagation.

To reduce the weight of a structure such as the fuselage and wing, fibre reinforced polymers have been incorporated into the metallic laminate. The application of aramid fibres in the laminate (Arall) in the Airbus A320 fuselage was studied, however the weight reduction in the wing was only around $8 \%$ against the eight to tenfold material price increase due to the various treatment processes involved in production of Arall [3]. It should be noted that larger weight savings (around 30\%) were achieved in wing structures on the same aircraft [3].

Further developments involved using glass fibre as an alternative for aramid fibre (known as Glare) in the Airbus A320 fuselage. This saved up to $25 \%$ weight of the fuselage and was more promising [3]. Other advantages of using Glare beside the weight saving and fatigue insensitivity is high impact resistance, corrosion resistance, flame resistance [4], excellent damage tolerance [5] and production simplification [6].

The enhanced performance of Glare provided the opportunity to further optimise the performance of structures. Numerically, Hagenbeek et al. [7] utilised the Stress-Strain Calculation Program (SSCP) to calculate the stress-strain response of any Glare 
configuration. This program included plasticity, residual stress after curing and the effect of pre-straining of the Glare during manufacture. Good agreement was found with the experimental stress-strain data. Further, they used a metal volume fraction method (MVF) to calculate blunt notch strength and shear yield strength of Glare. Good agreement with the experimental data was found for both cases and the predicted shear yield strength of Glare was accurate to better than $6.5 \%$. Kawai et al. [8] modelled the inelastic tensile stress-strain behaviour for Glare 2 using classical laminated plate theory (CLT). They predicted the stressstrain behaviour well and showed that the yield stress of Glare is similar to the yield of the metallic materials. The ultimate strength of Glare was also predicted using the Tsai-Hill failure criterion and the excellent agreement was found.

Large skin Glare sheets are required to manufacture a wing panel or body fuselage to reduce the amount of joints. Currently aluminium sheets with a maximum width of $1.60 \mathrm{~m}$ and a nominal thickness 0.3 and $0.5 \mathrm{~mm}$ can be manufactured [9]. The other limiting factors on producing large panels are pre-treatment, autoclave curing, and C-scan facilities. A design concept has been developed to overcome the joining problem and is termed the splice. The original spliced concept consisted of butted aluminium with the fibre layer bridging the splices (butts). However, this "butt splice" was found to be an unacceptable joining technique with early failure in the butts. Different designs of splice were assessed and finally a concept of an "overlap splice" was developed where the aluminium layers overlapped each other and were adhesively bonded [10]. As with the spliced concept in Glare, the thick, large panel of a wing cover can be manufactured by incorporating the Glare layer in the metal laminate. This can be done by replacing two aluminium layers in the aluminium laminate with Glare layers.

Because the lower wing panel is subjected to tension and bending during service, a local reinforcement (stringer) is bonded on the lower wing skin to increase the strength in spanwise direction. In addition the stringer can compensate for the reduction of strength of hybrid 
laminates due to the discontinuity (butt) in the Glare layers. However the bonded stringer can create local bending when it subjected to tension load [11] and this can affect the mechanical response, when the hybrid contains butts adjacent to the edge of bonded stringer. In this paper the mechanical response of hybrid fibre-metal laminate joints under static tensile loading is presented. The joints types include spanwise, chordwise without butts in the Glare sheets and chordwise with butts in the Glare sheets. As the Glare was provided in pre-manufactured sheets it was not possible to assess more complex forms of Glare sheet splicing. The configurations were determined by Airbus and considered appropriate for a preliminary testing programme.The specimens

have been subjected to tension load and the failure behaviour for each joint has been determined. Progressive damage numerical modelling has also been undertaken to predict the static response and failure mechanisms observed.

\section{Materials and Experimental Methods}

The hybrid fibre-metal laminate (FML) specimens (Fig. 1) were supplied by Airbus (Bristol, UK). The hybrid was manufactured using an autoclave and consisted of 4 layers of aluminium 2024-T3 of thickness $1.65 \mathrm{~mm}$, and 2 layers Glare 2B of thickness $1.66 \mathrm{~mm}$. Aluminium and Glare layers were bonded using the film adhesive FM 73M with a resulting bondline thickness of $0.22 \mathrm{~mm}$. Glare $2 \mathrm{~B}$ consisted of 3 layers of aluminium (with a measured layer thickness of $0.375 \mathrm{~mm}$ ) alternating with 2 layers of unidirectional S2 glass fibre/FM 94 epoxy (gfrp) (with a measured combined thickness of $0.267 \mathrm{~mm}$ ). There were gaps where the Glare layers butt end to end and these were filled with FM 73M adhesive. Unfortunately, post-manufacture, it was realised that poor surface preparation of the aluminium sheets led to non optimal (weak) bonding between aluminium sheet and 
aluminium sheet with Glare. The bonding within the Glare and of the stringer onto the laminate, which were the more important bonds, was optimal.

Specimens were cut from a larger panel. There were two kinds of specimens according to the fibre and aluminium rolling direction. The first is spanwise specimens (SP), where fibre and aluminium rolling direction ran along the specimen length, the second is chordwise without butt specimens (CH-NB), where fibre and aluminium rolling direction ran perpendicular to the specimen length. Some of the chordwise specimens contain two butts (between adjacent Glare layers). They were grouped as butt type-1 (CH-B1) and butt type-2 (CH-B2) based on the location of the butts. In CH-B1, the butts were located at non-critical locations (one butt inside the stringer and the other outside the stringer near the grip). In $\mathrm{CH}$ $\mathrm{B} 2$, the butts were located in the critical regions, (immediately under one of the stringer edges). The butt configuration being investigated was considerably simpler than the internal splicing technique discussed in the previous section. As a result it is likely to be less effective but this part of the work was being carried out to characterise these simpler butt configurations. The dimension of the specimens was similar for all joint configurations therefore only $\mathrm{CH}-\mathrm{B} 1$ and $\mathrm{CH}-\mathrm{B} 2$ have been shown in Fig. 2 to illustrate the location of the butts. The width of all specimens was $15 \mathrm{~mm}$. The configuration of specimens including the lay up of the laminate and butt positions were determined by Airbus.

Because the stringer was not bonded during the hybrid FML panel manufacturing, the stringers were bonded to the hybrid specimens after the specimens had been cut from a larger panel. The side of the hybrid specimen being bonded to the stringer was coated using BR 127 primer prior to bonding. The stringer material is aluminium 2024-T3. The dimension of stringer (thickness and length) selected (Fig. 2) was provided and recommended by Airbus as being representative. The surface of the stringer was treated using a CAE/PAA method and the surface being bonded to the hybrid was coated using BR 127 primer. 
The stringer was bonded to the FML using one side tacky film adhesive FM 73M from Cytec. One layer of FM 73M was laid up upon the FML and one on the stringer surface. The smooth surface of FM 73M was applied to the FML and stringer surfaces to reduce air entrapment. Both surfaces then were brought together. Before curing in the oven, the specimen was located in a jig to maintain the alignment of the stringer and the hybrid and to apply pressure during curing. The curing process was heating from room temperature to $120^{\circ} \mathrm{C}$ over 30 minutes followed by dwelling at $120^{\circ} \mathrm{C}$ for 60 minutes and then cooling in the oven overnight to reach the room temperature. The curing pressure was $0.28 \mathrm{MPa}$ according to the recommendation of the manufacturer [12]. Steel spacers were used to ensure an adhesive thickness of $0.2 \mathrm{~mm}$ was achieved.

Static testing was performed using an Instron testing machine having $100 \mathrm{kN}$ capacity. The laminates were gripped over a $40 \mathrm{~mm}$ length at either end (as shown in Fig 2) and then loaded, in tension, slowly. The crosshead rate was maintained at $0.1 \mathrm{~mm} / \mathrm{min}$ to allow sufficient time to observe the damage process. This was observed carefully using both visual and video microscopy techniques until complete failure of the specimen occurred. At these low rates, the effect of crosshead speed on the failure strength can be considered negligible, as this hybrid laminate contains over $80 \%$ volume fraction of aluminium layers which are insensitive to the test rate [13]. Furthermore, though the glass layer is sensitive to the test rate the contribution to increasing the failure strength of Glare has been found to be significant only at high test rates [13]. Thus very little rate dependency, if any, is to be expected in the tests reported in the current work.

A data logger was used to record load and crosshead displacement of the test machine. No extensometer was used due to difficulty in mounting on the specimen. Thus the measured displacement included the compliance of the load train (reversible) and slip in the machine (irreversible) as well as the specimen deformation. Adjustments to the experimental data 
were made to allow comparison between modelled and experimental responses later in this paper. Due to a limited number of specimens, only two replicates were tested, the results showed good consistency. Testing was carried out at room temperature $\left(20^{\circ} \mathrm{C}\right)$ in a laboratory environment.

\section{Experimental results}

\subsection{Static strength}

Table 1 shows the static strength of the hybrid FML joints. The static strength of the four types of specimen, from highest to lowest is $\mathrm{SP}>\mathrm{CH}-\mathrm{NB}>\mathrm{CH}-\mathrm{B} 1>\mathrm{CH}-\mathrm{B} 2$. It is clear that the SP specimen (where the fibre in the FML ran along the line of loading) supports a higher load than the $\mathrm{CH}$ specimen. When the $\mathrm{CH}$ contains butts the strength is reduced. It can be seen that the static strength of $\mathrm{CH}-\mathrm{B} 1$ where a butt is inside the stringer is higher than $\mathrm{CH}-\mathrm{B} 2$ where the butts are in the high stress region at the edge of stringer. The reduction of static strength due to the existence of a butt at a non critical location and a critical location is $23 \%$ and $29 \%$ respectively.

Fig. 3 shows a typical load displacement curve of each of the 4 configurations. It is clear that the initial slopes, in the elastic region, were the same. However, after around $30 \mathrm{kN}$, they start to deviate from each other, due to differences in load transfer capability and the inherent strength of the constituent materials. The displacement at final failure for all specimens is around $20 \%$ of their original length which is typical for aluminium 2024-T3 [14]. The detail of each failure process will be described in the failure behaviour section that follows.

\subsection{The observed failure mechanisms in the hybrid FML joints}

A summary of the failure mechanism observed from visual observation and in-situ video microscopy for each type of specimens is presented. Damage has been observed in the fillet 
of adhesive layer, the adhesive layer, the Glare, the aluminium layer and where appropriates the butts between the Glare layers. These failure mechanisms are synchronised with the loaddisplacement curve for each type of specimen.

\subsubsection{Spanwise}

Fig. 4 shows the failure behaviour of the SP specimen. In Fig. 4a, the load increased linearly until around $40 \mathrm{kN}$, then became nonlinear due to plastic deformation of aluminium layer. Starting from point $\mathbf{1}$, the adhesive fillet at both ends of the stringer began to damage and a crack was observed at load of $47 \mathrm{kN}$, (Fig. $4 \mathrm{~b}(1))$. The damage in the stringer adhesive layer was cohesive (indicating good bonding), and grew with increasing load. The loaddisplacement response was linear (with a reduced slope) due to the elastic deformation of gfrp until point $\mathbf{2}$. At point $\mathbf{2}$, the load reached a maximum value and then dropped abruptly. This occurrence is due to the failure of the aluminium layer in the centre of the lower Glare sheet together with the failure of both gfrp layers surrounding the failed aluminium layer (Fig. 4b(2)). During the rapid load fall a similar failure occurred in the upper Glare sheet followed by a further load drop (Fig. 4b(3), point 3). After the failure of both Glare layers, most of load was then carried by the 4 aluminium layers and 4 thinner aluminium layers in the Glare until both of the outer aluminium layers failed, point 4.

\subsubsection{Chordwise without butt}

Fig. 5 shows the failure process for the $\mathrm{CH}$ specimen. The failure process seems more complicated than for the SP specimen. It can be seen that the curve changed from linear to non linear at approximately the same load as for SP, around $40 \mathrm{kN}$. Further, from observation, failure in the adhesive fillet followed by cohesive damage in the stringer adhesive layer occurred at point $\mathbf{1}$, at around $47 \mathrm{kN}$. Curve $\mathbf{1}-\mathbf{4}$ is mainly due to the plastic 
deformation of aluminium layer, the propagation of damage in the adhesive layer, and delamination in the gfrp. As shown in Fig. 5(a), at point $\mathbf{2}$ and $\mathbf{3}$ (around $56 \mathrm{kN}$ ), there is very small drop in load, which is the delamination in the gfrp in both Glare layers, close to the gfrp/aluminium interface, as shown in Fig. 5b (2) and Fig. 5b (3), indicated by red arrow. Massive matrix cracking is also observed in the gfrp. The subsequent failure of the first and second Glare layers was observed at point 4 and point 5. It is different to the failure in the SP in which only the aluminium layer at the centre and the adjacent two layers of gfrp fail, in the $\mathrm{CH}$ all aluminium layers and gfrp failed at the same time. After losing the load carrying capability in the Glare, the two aluminium layers in the centre of specimen fail at the same time. So, in these specimens, the chord-wise oriented gfrp fails due to matrix cracking at a low load and the overall response is determined by the aluminium layers

\subsubsection{Chordwise with butt type-1}

Fig. 6 shows the failure process of chordwise with butt type- 1 specimens. At point 1 in Fig. 6a, around $37 \mathrm{kN}$, failure of the butt outside the stringer was observed (Fig. 6b(1)). As the load increased, the opening of the butts grew due to the straining of aluminium layer. As the butt could no longer transfer the load, the load was transferred to the adjacent aluminium layers. Following the failure of the butt, debonding between the adhesive and aluminium layer either side of the butt occurred. During this process the load still increased, due to the work hardening of the aluminium. At point 2, at approximately $42 \mathrm{kN}$, the adhesive fillet and the stringer adhesive layer began to fail and almost at the same time the outside butt has completely failed (Fig. 6b(2)). The damage in adhesive layer is not symmetric. Faster damage propagation occurred in the end of the adhesive layer closer to the failed butt. Curve $\mathbf{1}-\mathbf{3}$ is a combined process of plastic deformation, delamination and damage in the stringer bond line. 
Point $\mathbf{2}-\mathbf{3}$, where the load flattens, is mainly due to the delamination of the aluminium layers (due to poor surface preparation of the aluminium) and damage in the stringer bond

line. At point 3, when the crack length in the stringer adhesive layer approached within 10-15 $\mathrm{mm}$ of the butt inside the stringer, this butt then failed and the load dropped abruptly (Fig. $6 b(3))$. Following the load drop there was a long process of delamination between aluminium layers. After the delamination has finished, the aluminium in the outer layers failed, as shown in Fig. 6b(4-5).

\subsubsection{Chordwise with butt type-2}

Fig. 7 shows the failure process in $\mathrm{CH}$ with butt type- 2 specimens, where the butt is located in a critical position. At point 1, approximately $36 \mathrm{kN}$, both butts and the adhesive fillet began to fail (Fig. 7b). The long process after this damage is the combined process of the delamination between the aluminium and the Glare layers (due to poor surface preparation of the aluminium), cohesive damage in the stringer bondline and also plastic deformation of aluminium layers. Some irregularities in the inset graph in Fig. 7a indicate failure of the first and second butts and the onset of damage in the bonded stringer. Point 2 and $\mathbf{3}$ is the failure of the outer aluminium layers.

\section{Finite element (FE) modelling}

The hybrid FML consisted of aluminium, adhesive and gfrp layers (see Fig. 1). To model the static failure of the hybrid FML joints, progressive damage of the gfrp layer, the gfrpaluminium and aluminium-aluminium bondlines were simulated. The final aluminium failure was not modelled; however the aluminium plasticity was included in the model.

The gfrp layer was modelled using linear damage initiation and damage evolution, while the adhesive layers under the bonded stringer and in the laminate were modelled using 
cohesive zone elements. A cohesive model was also used to model the delamination in the resin rich region which existed at the interface between gfrp and aluminium and within the gfrp layer [15]. As mentioned in the materials and experimental methods and the experimental result sections, there are two bonding conditions, strong and weak bonding. The strong bonding is between laminate and stringer and between aluminium and gfrp in Glare. The weak bonding is between aluminium sheets and between the aluminium sheet and Glare. Therefore different cohesive properties will be assigned in the model.

In the chordwise specimens with butts, because there was no failure in the Glare layer, the entire Glare layer was modelled as an orthotropic material. The failure of the butts was modelled using a cohesive zone model.

\subsection{Material data for modelling}

Table 2 shows the elastic properties for Al 2024-T3 both in the longitudinal and in the transverse direction [14] and for adhesive FM 73M [16]. The longitudinal direction corresponds to the rolling direction during the manufacture of aluminium sheet and the transverse direction is perpendicular to the rolling direction. Table 3 shows the plasticity data for $\mathrm{Al} 2024-\mathrm{T} 3$ in longitudinal and transverse directions [17]. In the FE modelling the aluminium was modelled assuming isotropic behaviour but the longitudinal data was used for the spanwise specimens and the transverse data was used for the chordwise specimens.

As the specimen was subjected to tension load only, Hashin's criterion [18, 19] was used in the damage initiation criterion for unidirectional gfrp. Damage evolution was based on the fracture energy of gfrp in tension and in compression for the longitudinal and transverse directions. The value of Young's modulus, the ultimate strength in the longitudinal and transverse directions in both tension and compression respectively and shear modulus shown 
in Table 4, were taken from an Airbus report [20]. The value of fracture energy was based on Lapczyk and Hurtado [21].

To model the damage of the FM 73M adhesive layer in the bondlines and the butt a bilinear traction-separation law was employed. This bilinear traction separation law has been successfully employed in damage modelling of adhesive joints [22-25] and in composite laminate delamination [26-29]. Table 5 shows the properties of cohesive zone model. Cohesive-1 [24] represents the cohesive properties for the bonded stringer and butt where the bonding is good and cohesive- 2 is for the weaker laminate bonding. The cohesive properties of FM 73M (cohesive-1) have been well characterised in a study of the fracture of cantilever peel specimens taken from an aluminium 2024-T3 laminate [24] and then further applied to predict the static failure of aluminium 2024-T3 laminate joints (single lap joint and doubler in bending) [25]. The traction and fracture energy for cohesive-2 were obtained by reducing cohesive- 1 properties by a factor 0.45 . This reduction factor was determined by correlating the numerical and experimental failure mechanisms and ultimate load of chordwise with butt specimens.

The quadratic nominal stress and energy criterion were used to model damage initiation and damage evolution respectively. The quadratic nominal stress criterion considers the quadratic interaction between normal and shear tractions. The damage initiated when the interaction reached unity [30]. For damage evolution, mixed mode behaviour was employed by using a Benzeggagh and Kenane criterion [31] with the material parameter $\eta$ set as 1 .

Table 6 [32] and 7 [7] show, respectively, the equivalent orthotropic mechanical properties and plasticity data for the Glare layer as a whole. These data are only used for specimens with butts (where no damage was found in the Glare layers). The values were calculated from the aluminium and gfrp data shown in Table 2 - 4 using metal volume fraction (MVF) rules [7]. 


\subsection{Static modelling of the FML joints}

FE modelling was carried out in 2D using ABAQUS 6.9.1. This model did not consider the gripped region of the specimen. A fixed end boundary condition was applied on the left end of the FML joints. At the other end, kinematic coupling and displacement were applied. In the through-thickness direction the joint was restrained on the lower side only to allow for contraction (see Fig. 8). The element size in the cohesive section was approximately $0.2 \mathrm{~mm}$ x $0.2 \mathrm{~mm}$ (see Fig. 9). A 4-node bilinear plane strain quadrilateral element (CPE4R) was used in the aluminium layers, in the stringer and in the smeared Glare used with specimens with butts. The adhesive layers under the bonded stringer, in the laminate and in the resin rich gfrp-aluminium region were modelled using 4-node two dimensional cohesive elements (COH2D4). The gfrp was modelled using a 4-node bilinear plane stress quadrilateral element (CPS4R). The CPE4R element was also assigned to the adhesive in the larger butts; however a thin layer $(0.2 \mathrm{~mm})$ close to the GLARE-butt interface was modelled using cohesive elements to simulate the damage (see Fig. 8b).

To obtain convergence of the model during damage progression, regularisation was used both in the cohesive zone and in the gfrp elements. For the cohesive zone, the viscosity coefficient was set at a small value of $10^{-5} \mathrm{Ns} / \mathrm{m}^{2}$ while for gfrp the damage stabilisation was set as $0.00015 \mathrm{Ns} / \mathrm{m}^{2}$ for longitudinal and $0.0025 \mathrm{Ns} / \mathrm{m}^{2}$ for transverse directions for both tension and compression respectively. Further details of these convergence procedures can be found elsewhere in ABAQUS 6.9.1documentation [30].

\subsection{Results of finite element modelling and comparison with the experimental data}

The overall response for all configurations is considered first. This is followed by a detailed discussion for each of the 4 configurations analysed. 


\subsubsection{Static strength of FML joints}

The predicted static strengths and the comparison with the experimental data are seen in Table 1. It is seen that the FE modelling results are generally in good agreement with the experimental results. Fig. 10 shows the load-displacement response predicted from modelling which are also broadly consistent with the corresponding experimental data, shown in Fig. 3. Failure loads and the sequence of failure events are consistently predicted.

As discussed earlier, the actual predicted and experimental displacements do not agree due to the factors such as load train compliance and slipping as the FE model only considered the displacement of the specimen between the grip ends. The initial linear parts of the FE modelling were consistent with the stiffness estimates determined by simple hand calculations based on the extension of the aluminium and where appropriate the glass. Therefore the experimental displacements were adjusted by subtracting the machine compliance (a displacement proportional to the load) to give good agreement between the linear initial part of the experimental and modelled load displacement data. Even after this correction the final experimental displacement was found to be larger than that obtained by measuring the physically tested specimen. This was attributed to an irreversible slipping of the specimen relative to the machine (ie in the grips etc). A further adjustment was applied to match the experimental data at failure to the value obtained by measuring the specimen. This adjustment was applied linearly from the major yield point to the end of the test. The resulting adjusted experimental load-displacement data is compared with the FE data in Figs. 11-14 and generally a very reasonable correlation can be found.

\subsubsection{The failure behaviour of FML joints}

\section{a. Spanwise}


Fig. 11 shows the load-displacement response from FE modelling of the spanwise specimen together with a selection of relevant (von Mises equivalent stress and damage) contour plots for key events identified on the load-displacement response. The adjusted experimental curve is also shown for comparison. The correlation is remarkable.

Fig. $11 \mathrm{~b}$ shows the failure process for the spanwise joints. Secondary bending induced by the stringer caused a stress concentration near to the edge of stringer. At point $\mathbf{1}(40 \mathrm{kN})$, it can be seen that the load-displacement curve starts to change from linear to non linear due to plastic deformation of the aluminium layer near to the edge of stringer, where the highest plastic deformation occurs. It can be seen that the highest von Mises stress has reached 337 MPa (Fig. 11b(1), S, Mises) which exceeded the yield stress of Al 2024-T3 (around 300 MPa) [17]. The stringer bondline started to damage but no crack was seen yet. This was indicated by scalar damage variable for cohesive element (SDEG), the value of which had not reached 1 (fully damaged).

At point $2(66 \mathrm{kN})$, the gfrp layers in the upper Glare sheet carried most of the load and the load-displacement curve remains linear (but with a lower slope due to aluminium yielding) between point 2 and point 3 . The crack in the stringer bondline has propagated approximately $10 \mathrm{~mm}$ from the edge (Fig. $11 \mathrm{~b}(2))$. At point $3(83 \mathrm{kN})$, the load reached the maximum value with the initiation of failure of the gfrp layer in the upper Glare sheet, indicated by the damage variable for fibre in tension (DAMAGEFT). The von Mises stress reached $1500 \mathrm{MPa}$ which corresponded to the ultimate strength of gfrp layer. Delamination between the aluminium layers was observed on the left side of the laminate due to the weaker adhesive bond (Fig. 11b(3), SDEG). The failure of the gfrp in the lower Glare and also the extensive delamination between the aluminium layer and Glare and within the gfrp layers were observed at point 4 (Fig. 11b(4)). As a result of this sudden drop in load there will be a reduction in the load-train extension and this is transferred to a sudden increase in the 
specimen displacement (see experimental curve). In the FE model the displacement is applied at a constant strain rate and thus it cannot pick up this sudden increase in specimen displacement that accompanies the load drop in practice. The FE load following this dramatic failure event is higher than the experimental data as aluminium failure is not included in the FE but does occur in the aluminium in the Glare experimentally.

\section{b. Chordwise without butt}

Fig. 12a shows a comparison between modelling and adjusted experimental loaddisplacement curves for chordwise without butt specimens, while Fig. 12b shows a selection of contour plots for each point identified on the load-displacement plots. The correlation between modelling and experimental responses was very good. At point $\mathbf{1}(40 \mathrm{kN})$ again it can be seen that plastic deformation (PE max. in plane principal) occurred in the top aluminium layer near the edge of stringer as the von Mises stress ( $\mathrm{S}$, Mises) exceeded the yield stress of aluminium and the load-curve displacement started to become non linear. The damage (SDEG) in the stringer bondline started at this point but the crack initiated after point 2 where the SDEG value reached 1.

At point $2(52 \mathrm{kN})$ the plastic strain and the size of the plastic region increased as well as the damage in the stringer bondline. The gfrp in both Glare layers started to damage (DAMAGEFT), but the extent of the damage in the upper layer was higher than in the lower layer. This occured much earlier in this specimen than the SP specimen as the fibres are aligned transverse to the loading configuration and the stiffness and the strength in the loading direction are low. It seems that the upper adhesive layer in the laminate starts to damage close to the stringer edge. At point $3(54 \mathrm{kN})$, the crack in the stringer bondline has propagated to approximately $22 \mathrm{~mm}$ from the edge. Most of load was carried by the aluminium layer as the Young's modulus and the tensile strength of the gfrp in this direction 
is much lower than aluminium (see Table 2 and Table 4). The damage of the gfrp also extended along the layer. The more horizontal curve between point $\mathbf{2}$ and $\mathbf{3}$ was a combination of the damage in the stringer bondline and the plastic deformation in the aluminium layers.

At point $4(58 \mathrm{kN})$ the crack in the bonded stringer has almost reached the centre of joints (39 $\mathrm{mm}$ from the edge). The plasticity increased in all aluminium layers as the aluminium carried most of the load. Damage in the gfrp layer continued to increase until it was fully damage when the DAMAGEFT reached 1 at point $5(58.8 \mathrm{kN})$. Beyond this point the curve tends to drop due to more damage in the gfrp layer and extensive plastic deformation of the inner aluminium layer in the Glare (point 6). The delamination in the gfrp/aluminium interface region was not clearly observed in this 2D model because it does not consider widthwise deformation of the aluminium layers.

\section{c. Chordwise with butt type-1}

Fig. 13a compares the modelling and adjusted experimental load-displacement responses of chordwise with butt type-1 specimens. The correlation is excellent. Also shown in Fig. 13b are contour plots of von Mises stress (S, Mises), the plastic strain (PE max in-plane principal), and the damage parameter for the adhesive layers and the butt joints (SDEG) for each point indicated on the load displacement response.

At point 1 (approximately $37 \mathrm{kN}$ ) it was seen that the Mises stress distribution was not symmetric due to the asymmetry in the butt locations. The Glare layers which contain the butts have lower stress than the adjacent aluminium layers as the appropriate load cannot be transmitted through the more flexible (lower stiffness) butt region. High stress concentrations are seen in the upper aluminium layer at the stringer edge (indicated by the high plastic strain in this region) and the extent and the value increased after damage was seen here and in the 
lower butt at point $2(42 \mathrm{kN})$. Plastic strain which was seen initially at the edge of stringer only (point 1) extended to the aluminium layers adjacent to the butt and the value was high at the ends of butt, where the load is transferred through shear lag to the aluminium layers surrounding the butt.

The butt outside the stringer completely failed when there was sufficient deformation for this to occur and the adjacent aluminium exceeded the yield point. The failure of this butt was then followed by delamination in the Glare layer adjacent to the butt. During this delamination the load increased, however it tended to flatten after a certain level of delamination. At this point (around $45 \mathrm{kN}$ ) the stringer bondline started to fail (point 3). This bondline failure (and the Glare delamination) continued to grow with no significant change in load until it was approximately $20 \mathrm{~mm}$ from the butt inside the stringer. At this stage the internal butt failed and the load dropped sharply (point 4). The dropping of load was followed by the delamination process of Glare adjacent to this butt in the opposite direction. The final failure process seen in the experimental data is failure of one of the aluminium layers. This is not seen in the FE data as aluminium failure has not been included in the analysis.

\section{d. Chordwise with butt type-2}

Fig. 14a shows the modelling and adjusted experimental load-displacement curves for chordwise with butt type- 2 specimen. A selection of contour plots at points indicated on the loading responses is shown in Fig. 14b. As for all other joints, there was good correlation between the experimental and predicted responses. At point $1(37 \mathrm{kN})$ both butts failed together. As with the butt type-1 specimen, the butts in this joint completely failed when there was sufficient deformation for this to occur and the adjacent aluminium exceeded the yield point. A plastic strain concentration was seen in the upper aluminium layer at the end of 
stringer where the butts were located. After the butts failed, the load still slightly increased due to further plastic deformation of aluminium.

At point $2(39 \mathrm{kN})$, the crack in the stringer bondline initiated after delamination of the adhesive in the laminate reached a certain level and it reached the middle of joint at point $\mathbf{3}$. The crack and the delamination propagated with no significant change in load. The plastic deformation of the aluminium layers dominated the failure process. It can be seen that the upper aluminium layer experienced the highest plastic strain (point 3) with the Glare layers carrying no load due to the butt failures, therefore this point is considered as the failure point for this configuration. The final failure process seen in the experimental data is failure of one of the aluminium layers. This is not seen in the FE data as aluminium failure has not been included in the modelling.

\section{Conclusions}

Experimental static testing and FE modelling have been carried out on the hybrid FML joints. The key findings are outlined as follows:

1. The properties and damage of the constituent components of hybrid FML affect the static response in a complex manner. There was close correlation between FE modelling and experimental observation not only in terms of predicted failure loads but also in the individual failure mechanisms.

2. The static strength of hybrid joints is higher when the fibre direction is parallel to the loading direction than when the fibre is perpendicular to the loading direction.

3. The failure of Glare controls the ultimate load for both spanwise and chordwise specimens, however for chordwise specimens with butts, the failure of butt also plays an important role. 
4. The bonded stringer does not significantly affect the ultimate load of hybrid joints, but it affects the load-displacement response.

5. Butts play a role in the reduction of the static strength. The position of butt has an important affect. The most damaging location for the butt joints is at the stringer ends.

6. Progressive damage modelling, incorporating multiple potential failure mechanisms have been successfully undertaken for these joints.

7. Bi-linear traction-separation laws have been successfully employed to model the failure in the stringer bondline, delamination in the adhesive layer in the laminate, delamination within the gfrp layer and the damage in the butt, both in static strength and in the failure mechanism.

8. Hashin's criterion has been successfully employed to model the damage in the gfrp layer subjected in tension loading.

\section{Acknowledgements}

The authors would like to thanks to Airbus (Bristol, UK) which has supplied the hybrid FML and stringer material. Also thanks to Directorate General of Higher Education, Ministry of Education, Republic of Indonesia which support funding in this research.

\section{References}

[1] Vlot A. Glare. History of the Development of a New Aircraft Material. Dordrecht: Kluwer Academic Publishers, 2002.

[2] Schijve J, Van Lipzid HTM, Van Gestel GFJA, and Hoeymakers AHW. Fatigue properties of adhesively-bonded laminated sheet materials of aluminium alloys. Engineering Fracture Mechanic 1979; 12: 561-579.

[3] Vlot AD. Historical overview. In: Vlot AD, Jan Willem Gunnink, editor. Fiber Metal Laminates. An Introduction. Dordrecht: Kluwer Academic Publishers, 2001. p. 3-21.

[4]. Vogelesang LB, and Vlot A. Development of fiber metal laminates for advanced aerospace structures. Journal of Material Processing and Technology 2000; 103: 1-5.

[5] Alderliesten RC, Homan JJ. Fatigue and damage tolerance issues of Glare in aircraft structures. International Journal of Fatigue 2006; 28: 1116-1123. 
[6] Asundi A, and Choi AYN. Fiber metal laminates: An advanced material for future aircraft. Journal of Material Processing and Technology 1997; 63: 384-394.

[7] Hagenbeek M, Van Hengel C, Bosker OJ, and Vermeeren CAJR. Static properties of fiber metal laminates. Applied Composite Materials 2003; 10: 207-222.

[8] Kawai M, Morishita M, Tomura S, and Takumida K. Inelastic behaviour and strength of fiber-metal hybrid composite: Glare. International Journal of Mechanical Sciences 1998; 40(2-3): 183-198.

[9] de Vries TJ, Vlot A, Hashagen F. Delamination behavior of spliced Fiber Metal Laminates. Part. 1 Experimental result. Composite Structures 1999; 46: 131-145.

[10] Van der Jagt OC, and Out BCL. Detailed design concepts. In: Vlot AD, Jan Willem Gunnink, editor. Fiber Metal Laminates. An Introduction. Dordrecht: Kluwer Academic Publishers, 2001. p. 267-280.

[11] Woerden HJM, Mortier WJ, Guijt CB, Verhoven S. Bonded repair patches. In: Vlot AD, Jan Willem Gunnink, editor. Fiber Metal Laminates. An Introduction. Dordrecht: Kluwer Academic Publishers, 2001. p. 451-475.

[12] Cytec Engineered Materials. FM® 73 Toughened Epoxy Film. Maryland, 1998.

[13] Varas JM, Soetens F, Kroon E, van Aanhold JE, van der Meulen OR, and Sagimon M. Fracture and strain rate behavior of airplane fuselage materials under blast loading. In: EPJ Web of Conferences 2010; 6: 2017. http:dx.doi.org/10.1051/epjconf/20100642017 accessed on 10 December 2010.

[14] Airbus report. Airbus Material Specification: Aluminium alloy (2024) solution treated and naturally aged (T3). Ref. no. AIMS03-04-038, 2006.

[15] de Vries TJ, and Vlot A. The influence of the constituent properties on the residual strength of Glare. Applied Composite Materials 2001; 8: 263-277.

[16] Liljedahl CDM, Crocombe AD, Wahab MMA, Aschroft IA. Modelling the environmental degradation of the interface in adhesively bonded joints using cohesive zone approach. The Journal of Adhesion 2006; 82: 1061-1089.

[17] Khoramishad H. Modelling fatigue damage in adhesively bonded joints. PhD Thesis. University of Surrey, Guildford, UK, 2010.

[18] Hashin Z, and Rotem A. A fatigue criterion for fiber-reinforced materials. Journal of Composite Materials 1973; 7: 448-464.

[19] Hashin Z. Failure criteria for unidirectional fiber composites. Journal of Applied Mechanics 1980; 47: 329-334.

[20] Airbus report. Airbus Material Specification: Unidirectional glass fibre reinforced epoxy prepreg for application in Fibre Metal Laminates (FML). Ref. no. AIMS05-13-001, 2007.

[21] Lapczyk I, and Hurtado JA. Progressive damage modelling in fiber reinforced materials. Composites: Part A 2007; 38: 2333-2341.

[22] Liljedahl CDM, Crocombe AD, Wahab MA, Ashcroft IA. Damage modelling of adhesively bonded joints. International Journal of Fracture 2006; 141(1):147-161.

[23] Liljedahl CDM, Crocombe AD, Wahab MMA, Ashcroft IA. Modelling the environmental degradation of adhesively bonded aluminium and composite joints using a CZM approach. International Journal of Adhesion \& Adhesives 2007; 27: 505-518.

[24] Katnam K, Sargent JP, Crocombe AD, Khoramishad H, Ashcroft IA. Characterisation of moisture-dependent cohesive zone properties for adhesively bonded joints. Engineering Fracture Mechanic 2010; 77: 3105-3119.

[25] Katnam KB, Crocombe AD, Khoramishad H, Ashcroft IA. The Static failure of adhesively bonded metal laminate structures: A cohesive zone approach. Submitted to Journal of Adhesion Science and Technology 2009. 
[26] Bianchi S, Corigliano A, Frassine R, Rink M. Modelling of interlaminar fracture processes in composites using interface elements. Composites Science and Technology 2006; 66: 255-263.

[27] Alfano G, And Crisfield MA. Finite element interface models for the delamination analysis of laminated composites: Mechanical and computational issues. International Journal for Numerical Methods in Engineering 2001; 50:1701-1736.

[28 Turon A, Camanho PP, Costa J, Davila CG. A damage model for the simulation of delamination in advanced composites under variable-mode loading. Mechanics of Materials 2006; 38: 1072-1089.

[29] Geubelle PH, and Baylor JS. Impact-induced delamination of composites: A 2D simulation. Composites: Part B 1998; 29B: 589-602.

[30] ABAQUS. User Manual, version 6.9.1. Habbit, Karlsson \& Sorensen, Inc., USA, 2009.

[31] Benzeggagh ML, and Kenane M. Measurement of mixed-mode delamination fracture toughness of unidirectional glass/epoxy composites with mixed-mode bending apparatus. Composites Science and Technology 1996; 56: 439-449.

[32] Airbus report. Airbus Material Specification: Fibre metal laminates of glass fibre reinforced aluminium for application at $-55^{\circ} \mathrm{C}$ to $80^{\circ} \mathrm{C}$. Type 2 . Ref. no. AIMS 03-14$001,2005$. 


\section{LIST OF FIGURES CAPTION}

Fig. 1. A specimen of hybrid FML.

Fig. 2. The configuration and dimensional detail of hybrid FML joints (a) CH-B1, (b) CH-B2.

Fig. 3. Load-displacement curves for hybrid FML joints under tension loading.

Fig. 4. (a) Showing load level when the failure observed, (b) Schematic of failure process of SP specimen under static tension.

Fig. 5. (a) Showing load level when the failure observed, (b) Schematic of failure process of $\mathrm{CH}-\mathrm{NB}$ specimen under static tension.

Fig. 6. (a) Showing load level when the failure observed, (b) Schematic of failure process of $\mathrm{CH}-\mathrm{B} 1$ specimen under static tension.

Fig. 7. (a) Showing load level when the failure observed, (b) Schematic of failure process of $\mathrm{CH}-\mathrm{B} 2$ specimen under static tension.

Fig. 8. Schematic of boundary condition for (a) Full model for spanwise and chordwise,

(b) Full model for chordwise with butt.

Fig. 9. Showing meshing for model of doubler hybrid FML, (a) Meshing for SP and CH-NB, (b) Meshing for $\mathrm{CH}-\mathrm{B} 1$.

Fig. 10. Load-displacement doubler hybrid FML obtained from modelling.

Fig. 11. (a) Load-displacement response of SP from FE modelling and experimental, (b)

Modelling contour plot for SP (deformation scale factor is 10).

Fig. 12. (a) Load-displacement response of CH-NB from FE modelling and experimental, (b) Modelling contour plot for CH-NB (deformation scale factor is 1).

Fig. 13. (a) Load-displacement response of CH-B1 from FE modelling and experimental, (b) Modelling contour plot for $\mathrm{CH}-\mathrm{B} 1$ (deformation scale factor is 1 ).

Fig. 14. (a) Load-displacement response of $\mathrm{CH}-\mathrm{B} 2$ from FE modelling and experimental, (b) Modelling contour plot for $\mathrm{CH}-\mathrm{B} 2$ (deformation scale factor is 1). 


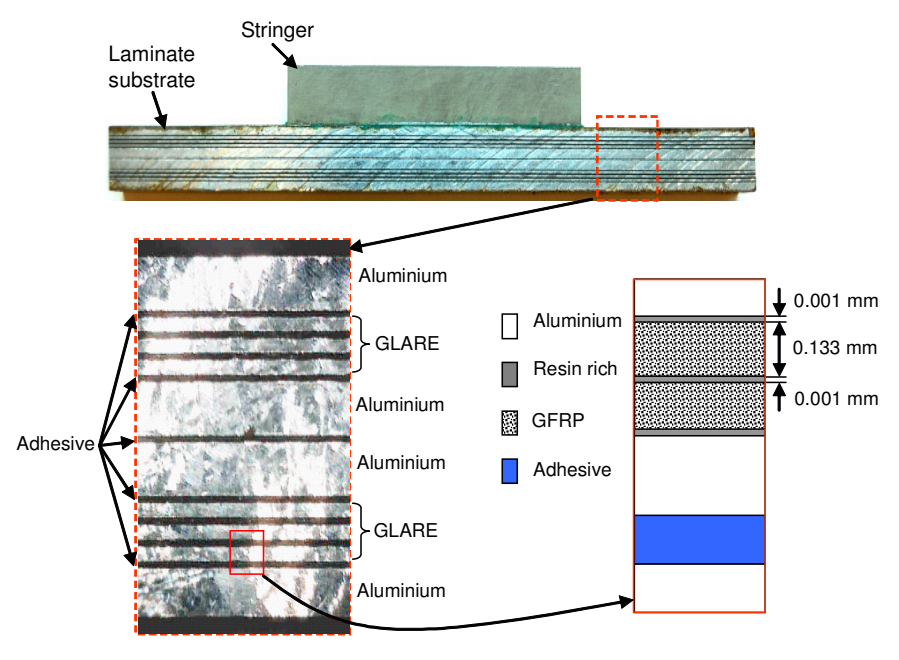

Fig. 1. A specimen of hybrid FML.

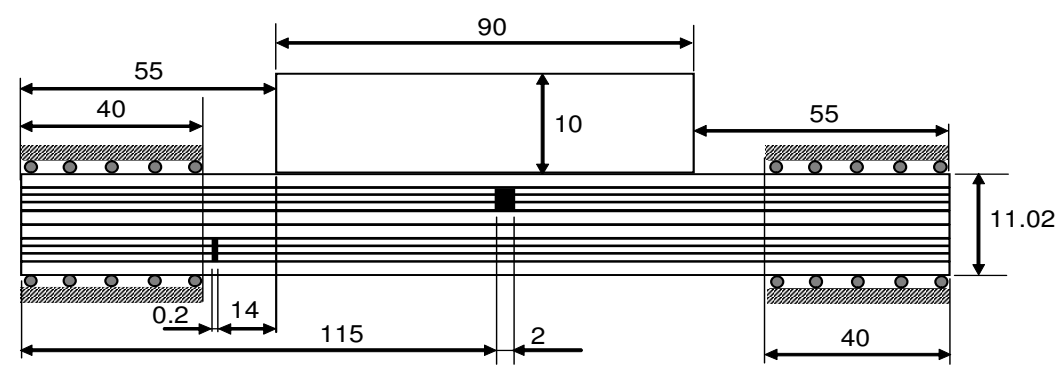

(a)

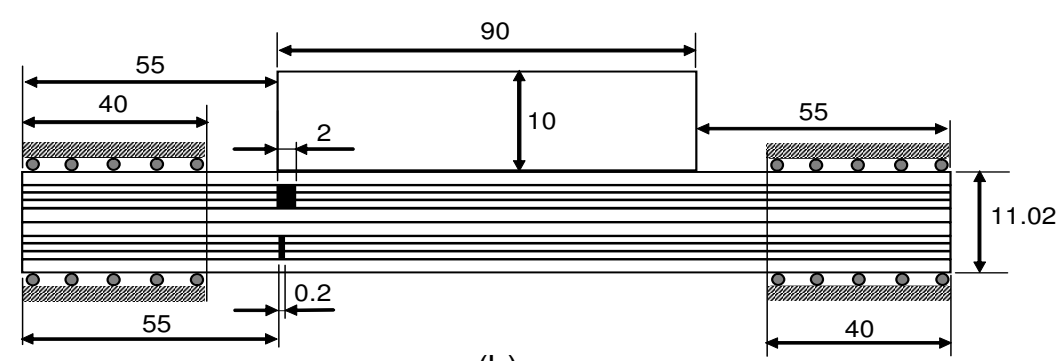

(b)

Specimen width $=15 \mathrm{~mm}$

Unit $=\mathrm{mm}$

Fig. 2. The configuration and dimensional detail of hybrid FML joints (a) $\mathrm{CH}-\mathrm{B} 1$, (b) $\mathrm{CH}-\mathrm{B} 2$. 


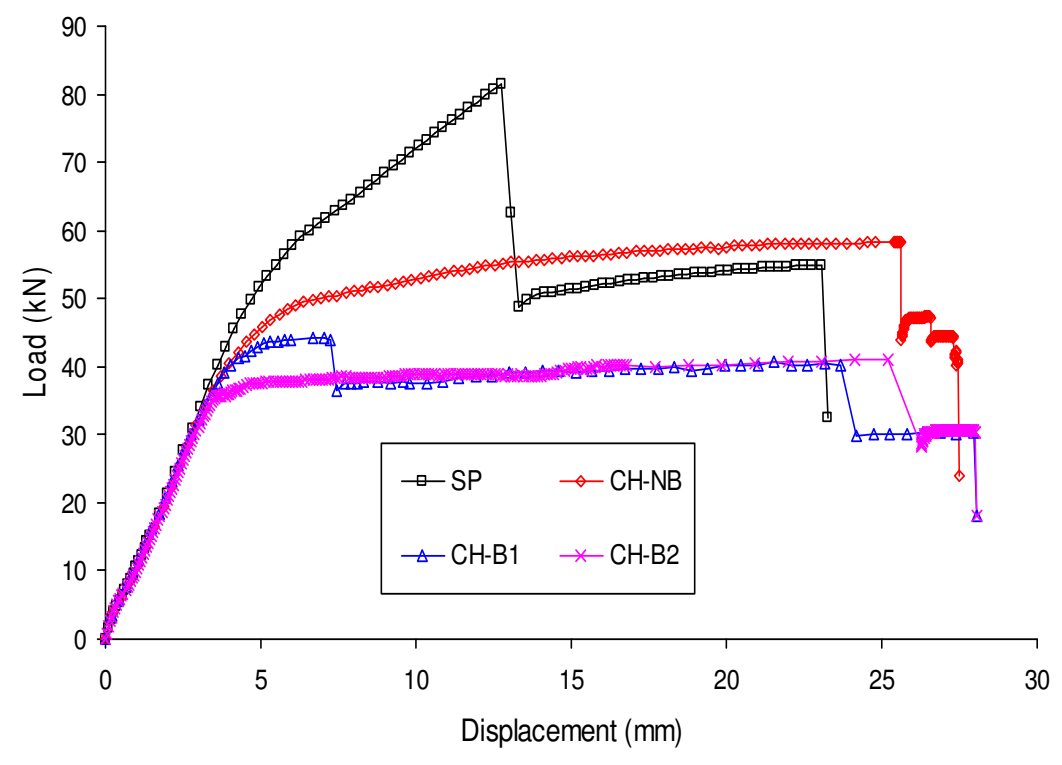

Fig. 3. Load-displacement curves for hybrid FML joints under tension loading.

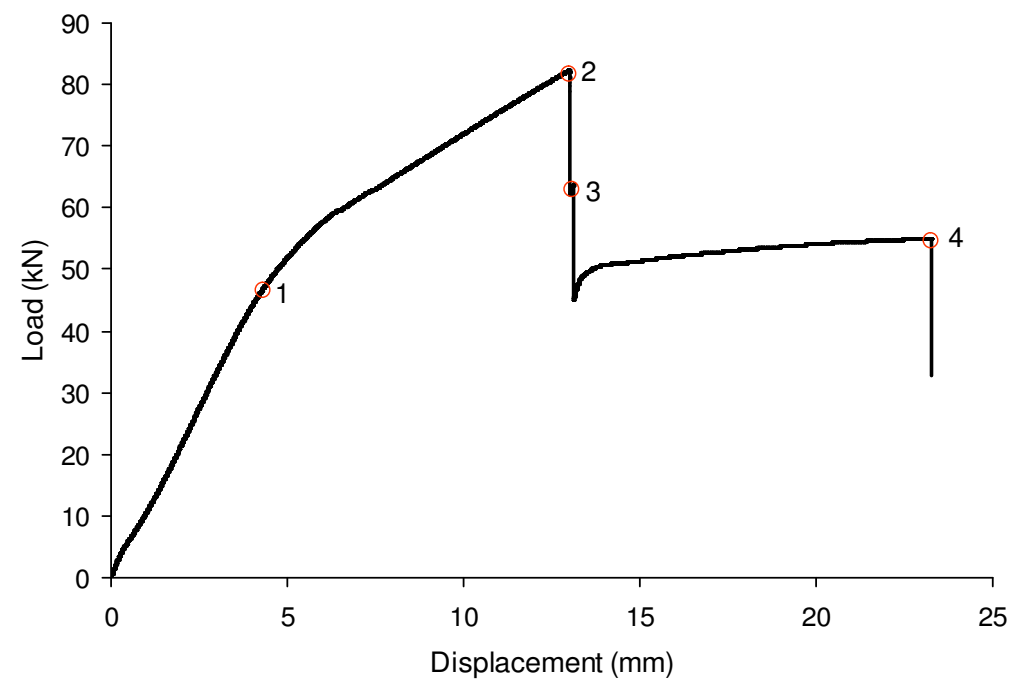


(a)
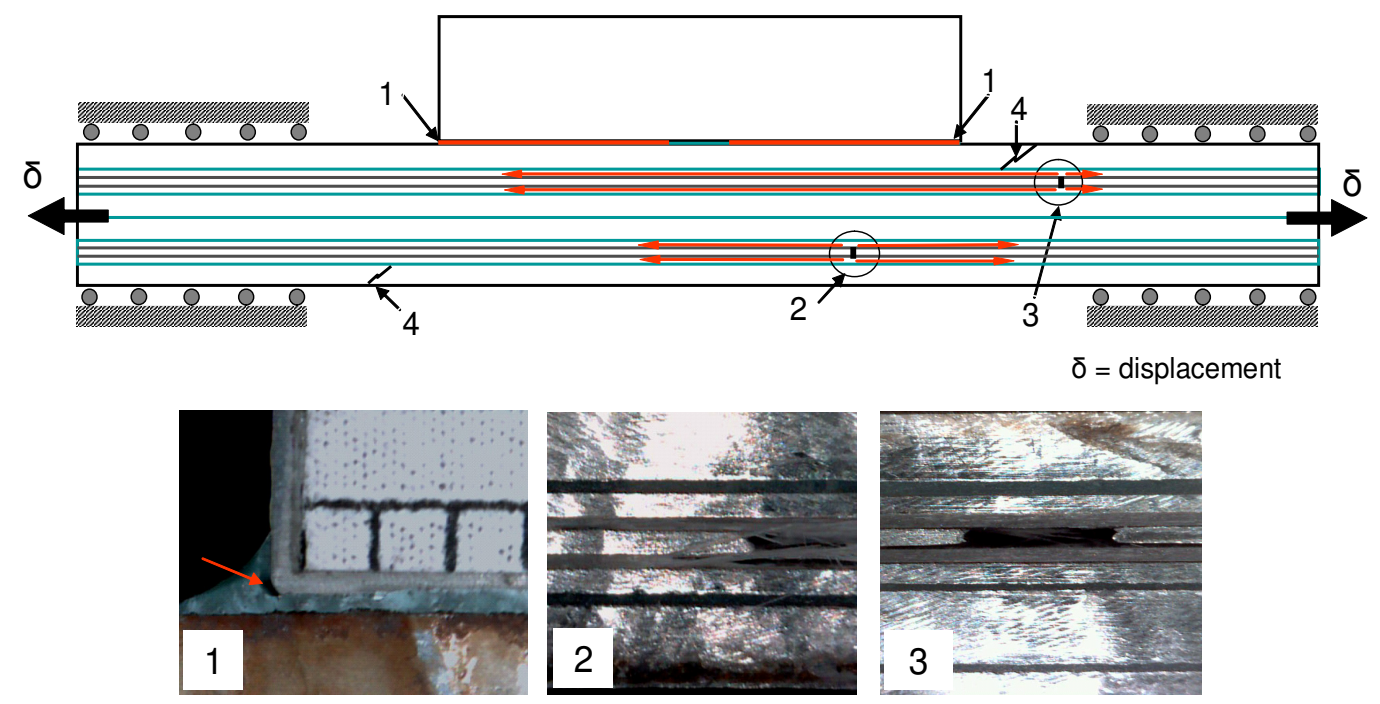

(b)

Fig. 4. (a) Showing load level when the failure observed, (b) Schematic of failure process of SP specimen under static tension.

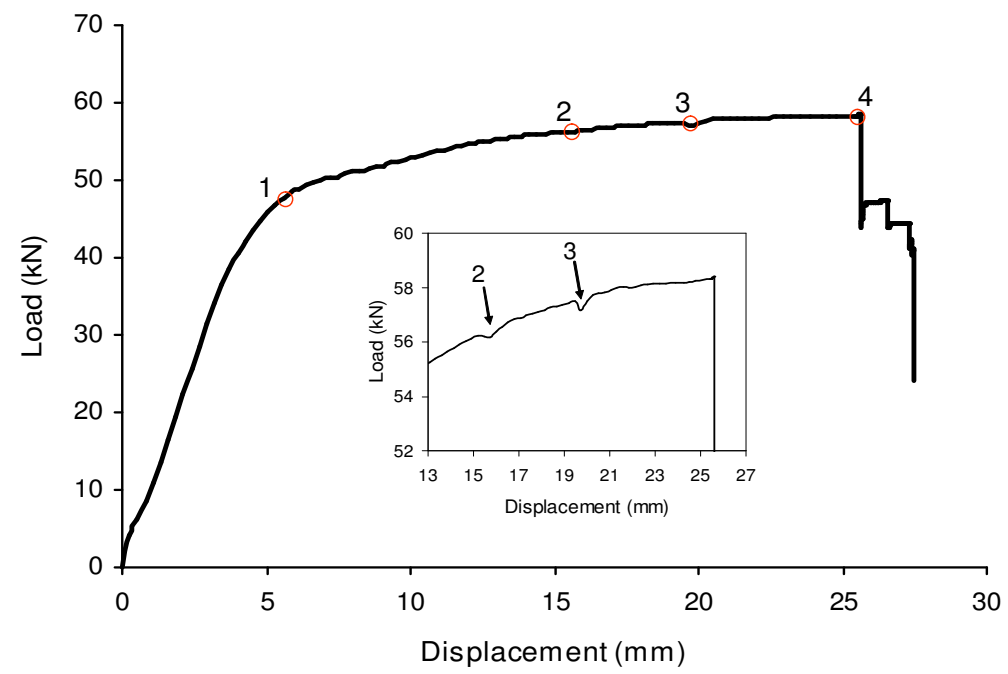

(a) 


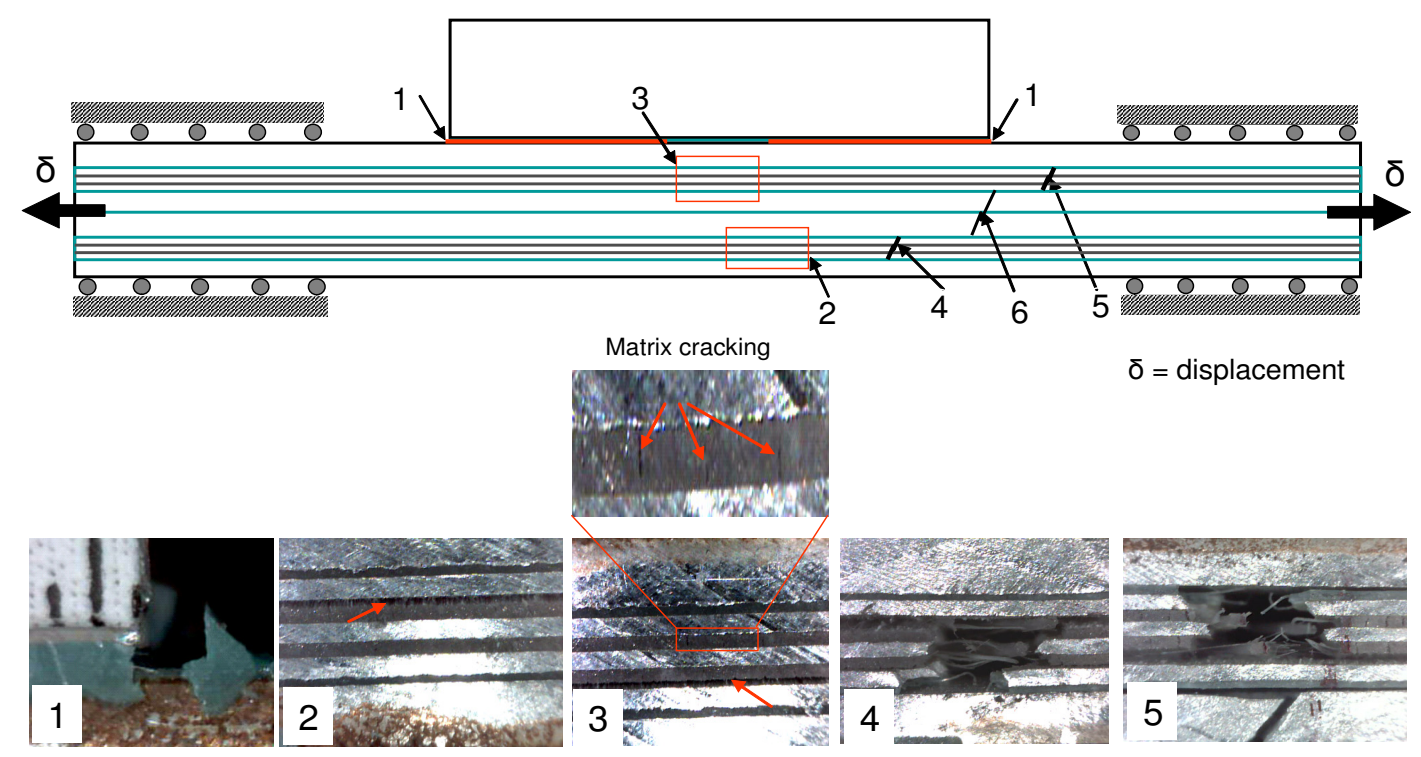

(b)

Fig. 5. (a) Showing load level when the failure observed, (b) Schematic of failure process of CH-NB specimen under static tension.

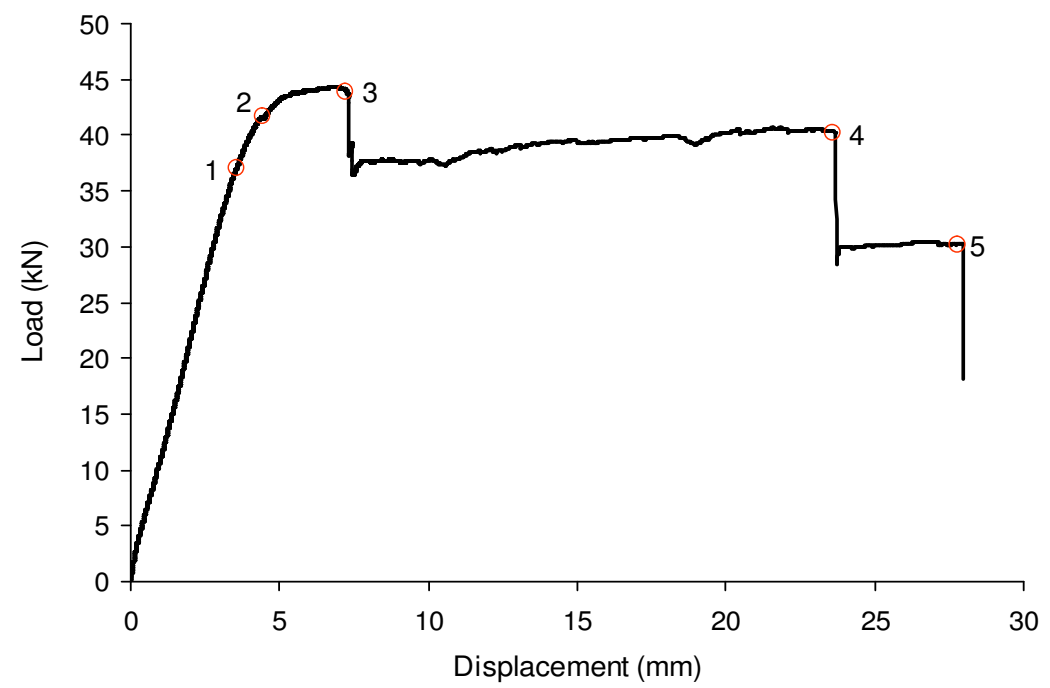

(a) 

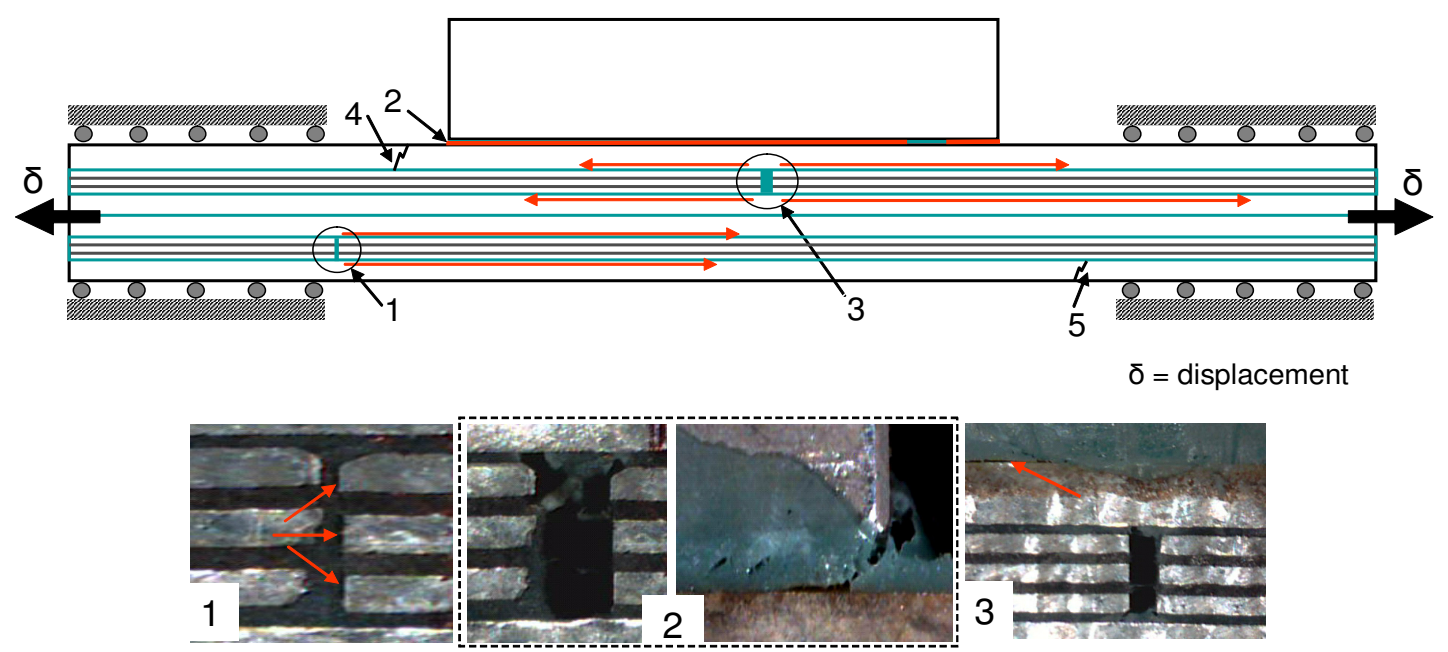

(b)

Fig. 6. (a) Showing load level when the failure observed, (b) Schematic of failure process of

CH-B1 specimen under static tension.

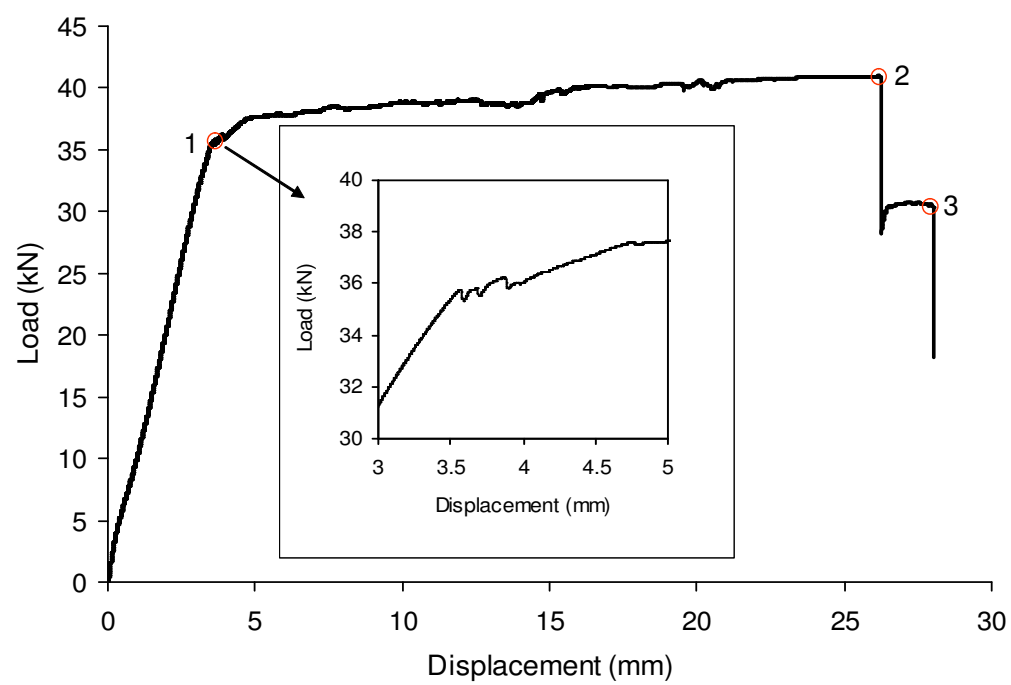

(a) 

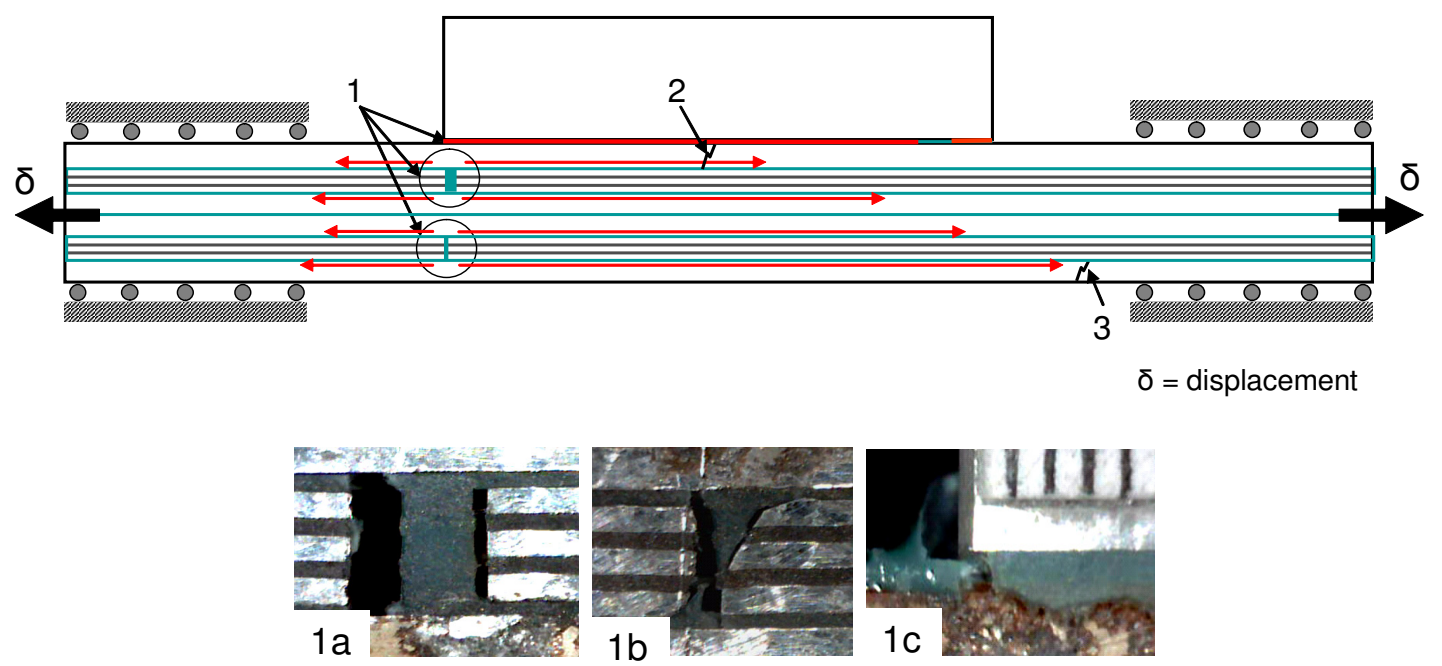

(b)

Fig. 7. (a) Showing load level when the failure observed, (b) Schematic of failure process of $\mathrm{CH}-\mathrm{B} 2$ specimen under static tension.
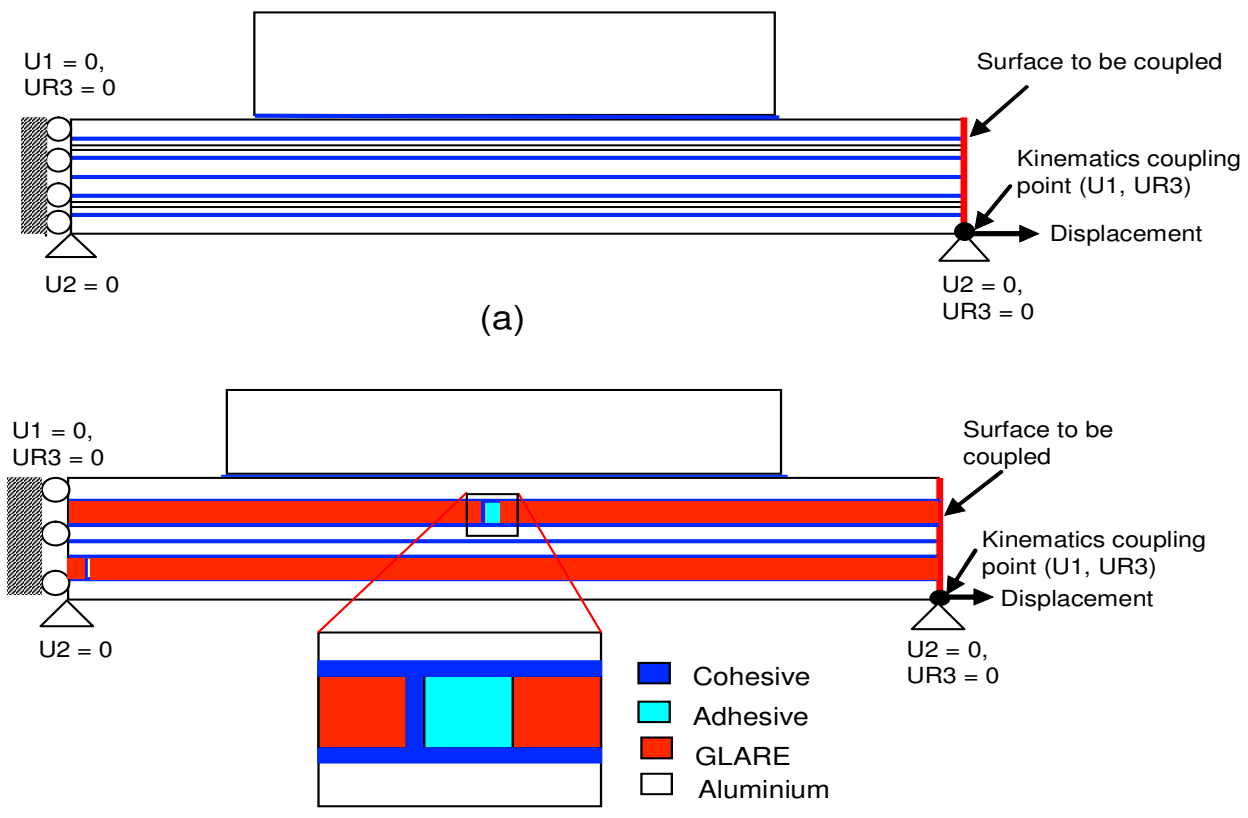

(b)

Fig. 8. Schematic of boundary condition for (a) Full model for spanwise and chordwise, (b) Full model for chordwise with butt. 


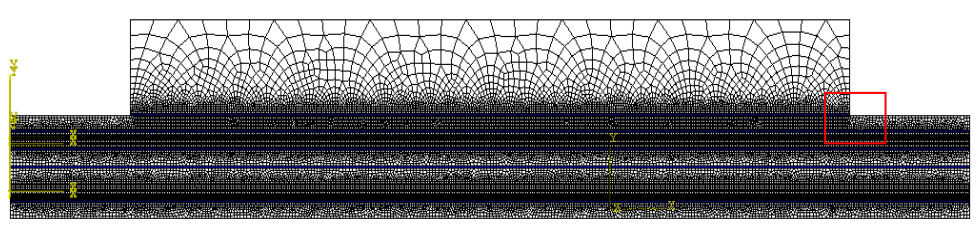

(a)

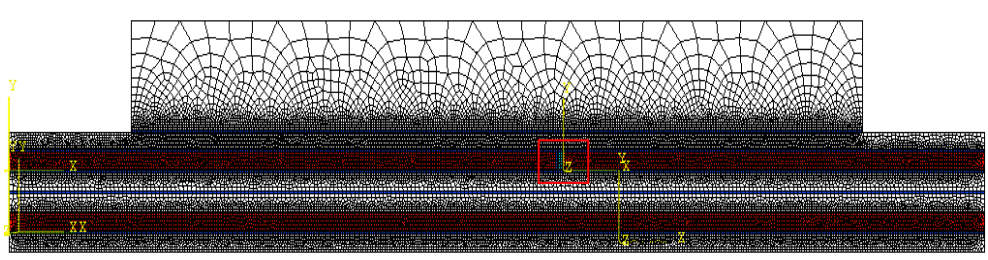

(b)
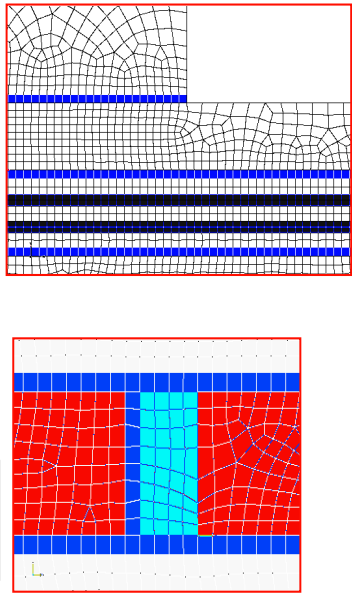

Meshing in butt

Fig. 9. Showing meshing for model of doubler hybrid FML, (a) Meshing for SP and CH without butt, (b) Meshing for CH-B1.

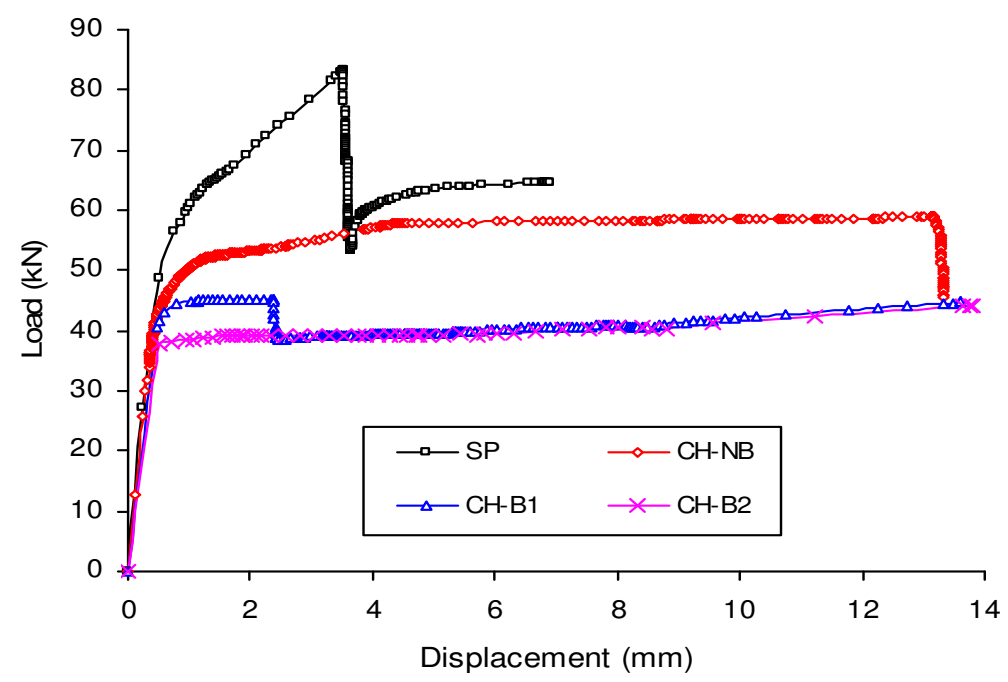

Fig. 10. Load-displacement response of doubler hybrid FML joints obtained from modelling. 


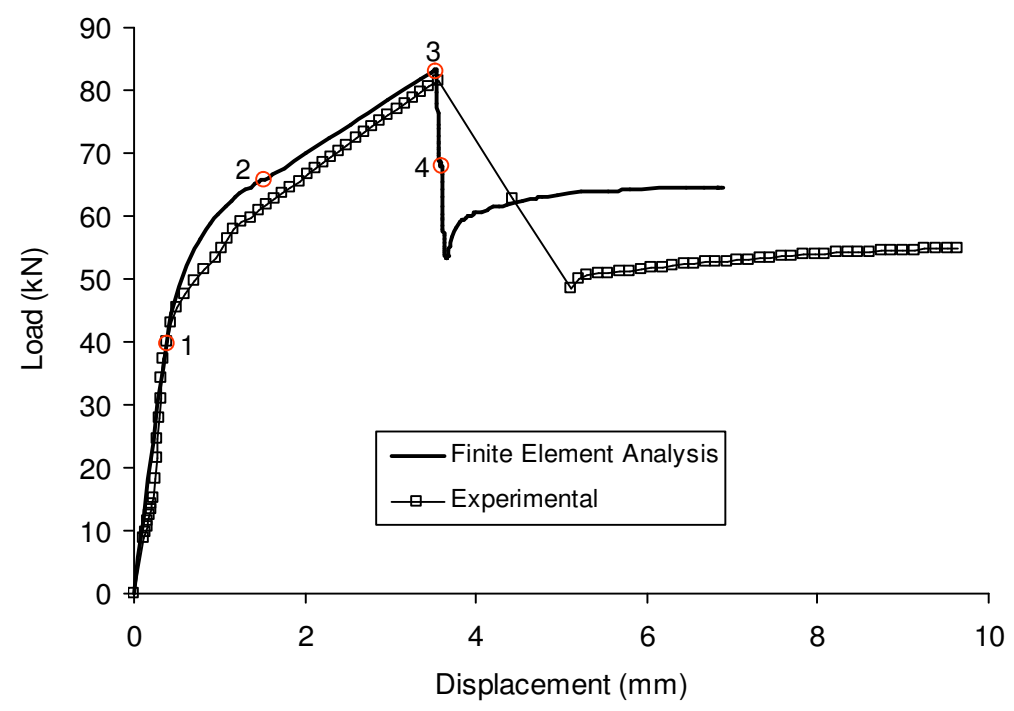

(a) 

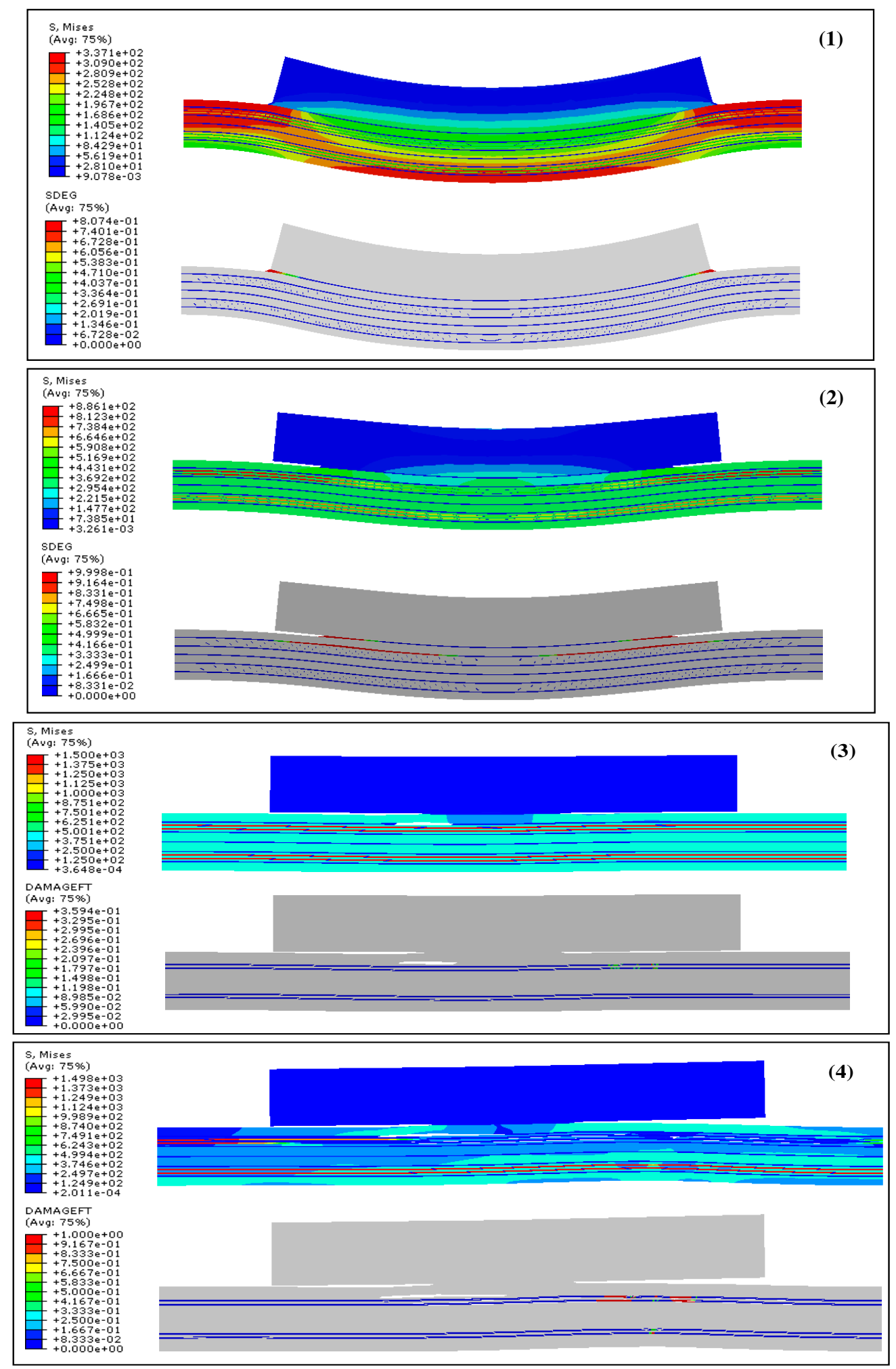

(b)

Fig. 11. (a) Load-displacement response of SP from FE modelling and experimental, (b)

Modelling contour plot for SP (deformation scale factor is 10). 


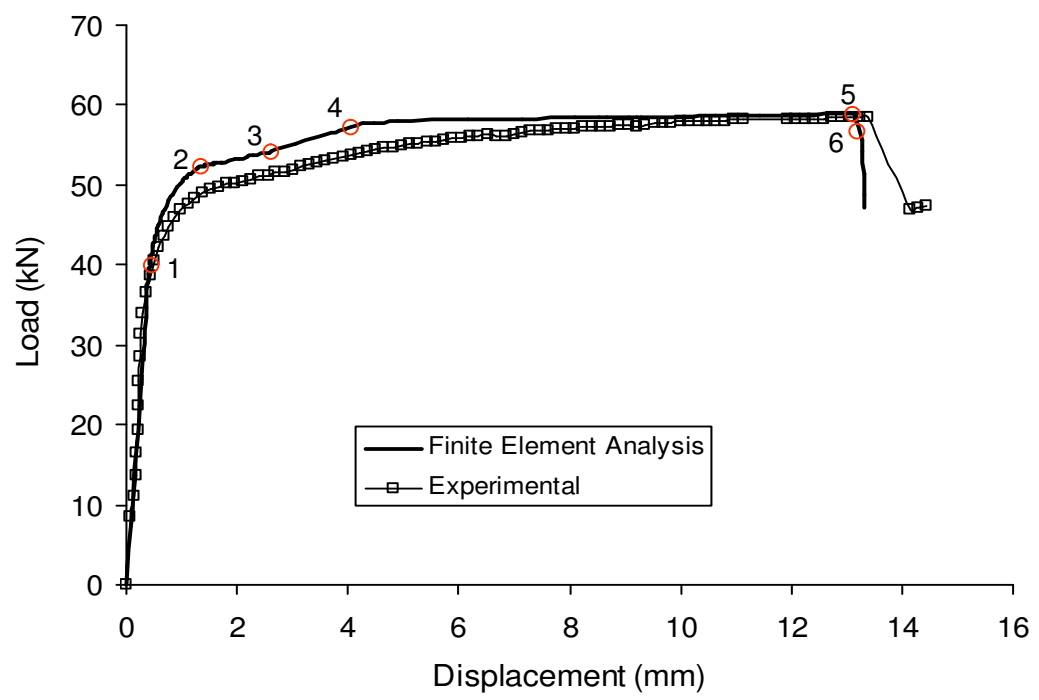

(a)
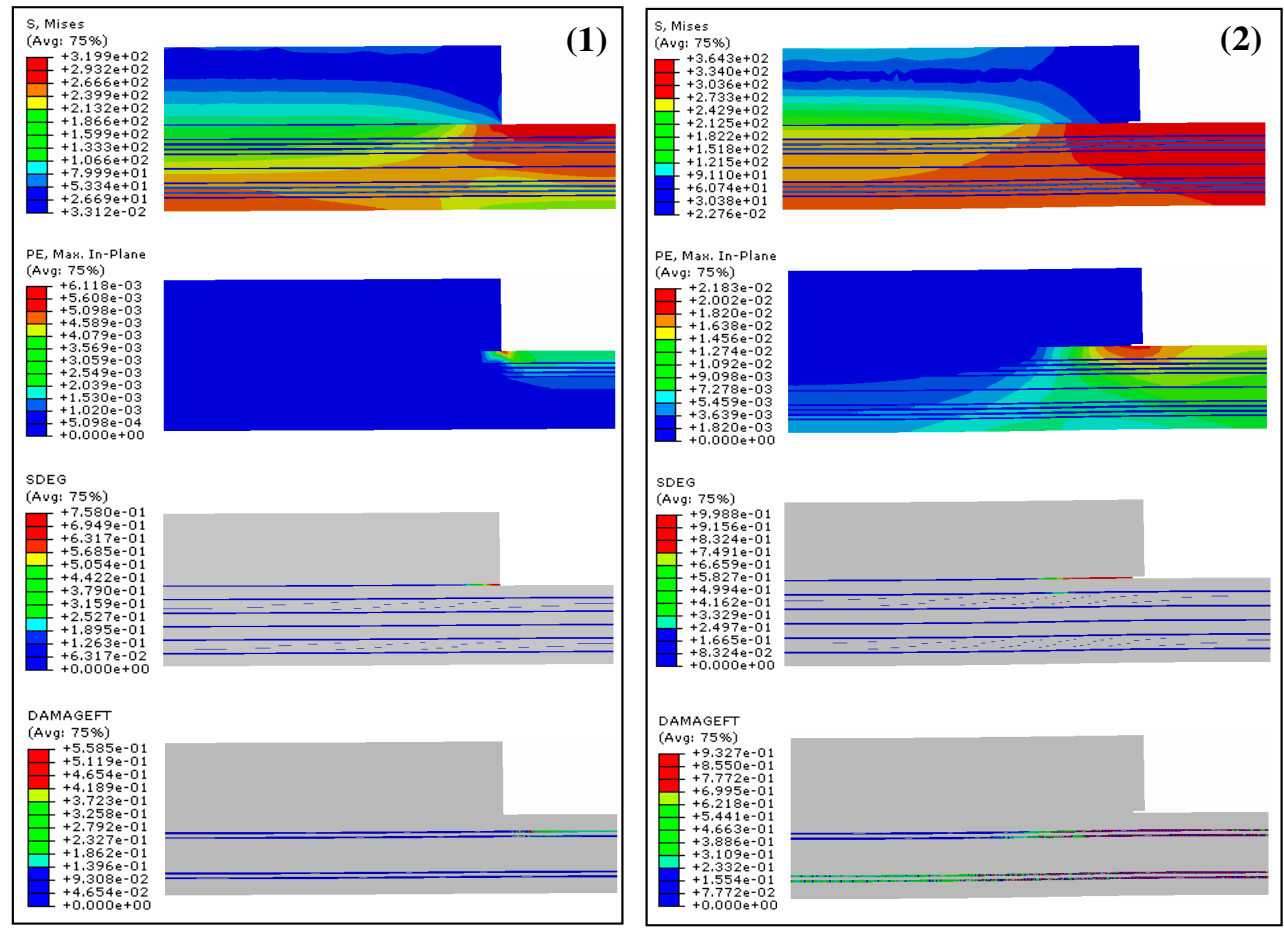

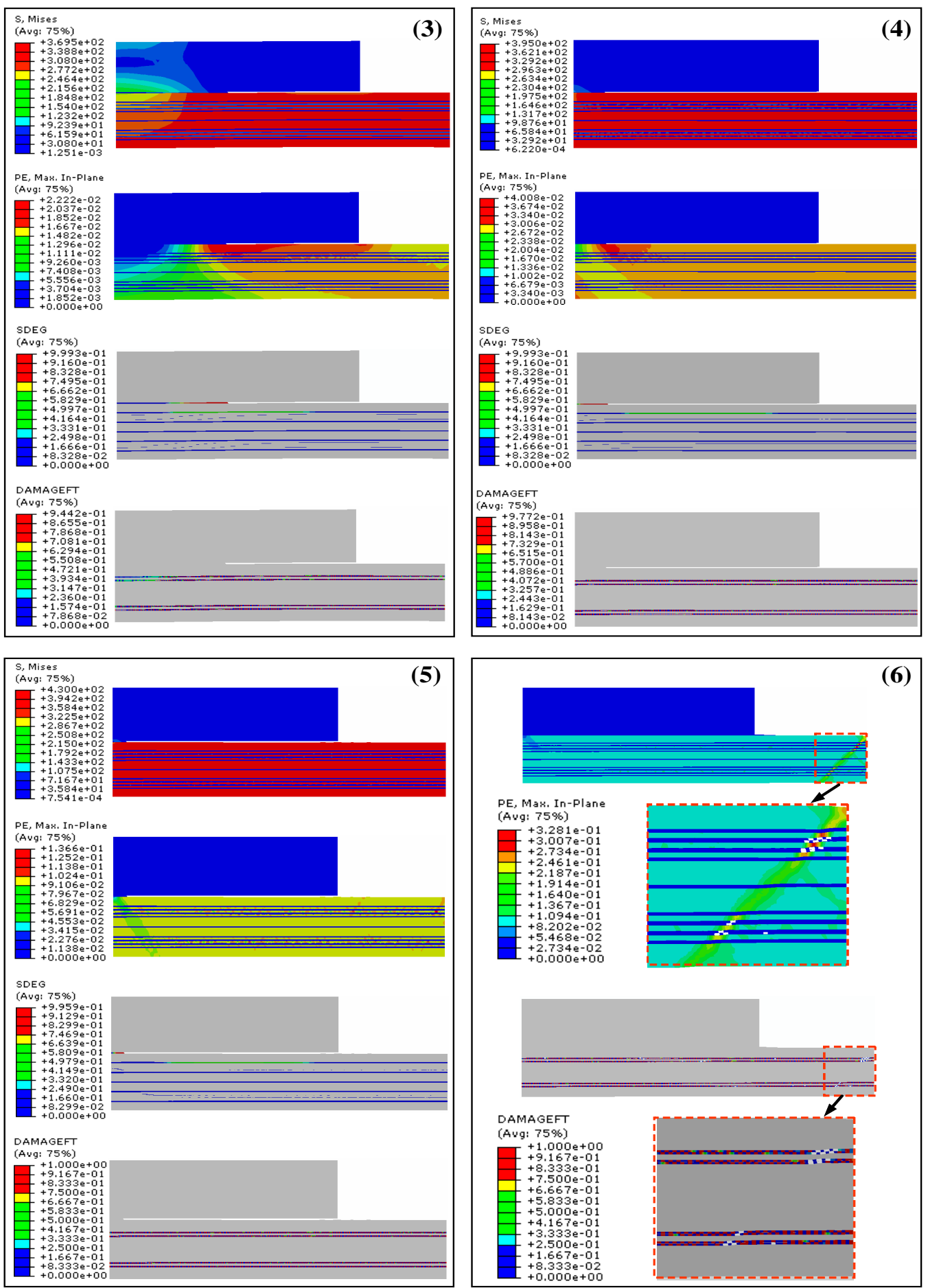

(b)

Fig. 12. (a) Load-displacement response of $\mathrm{CH}-\mathrm{NB}$ from FE modelling and experimental, (b) Modelling contour plot for CH-NB (deformation scale factor is 1). 


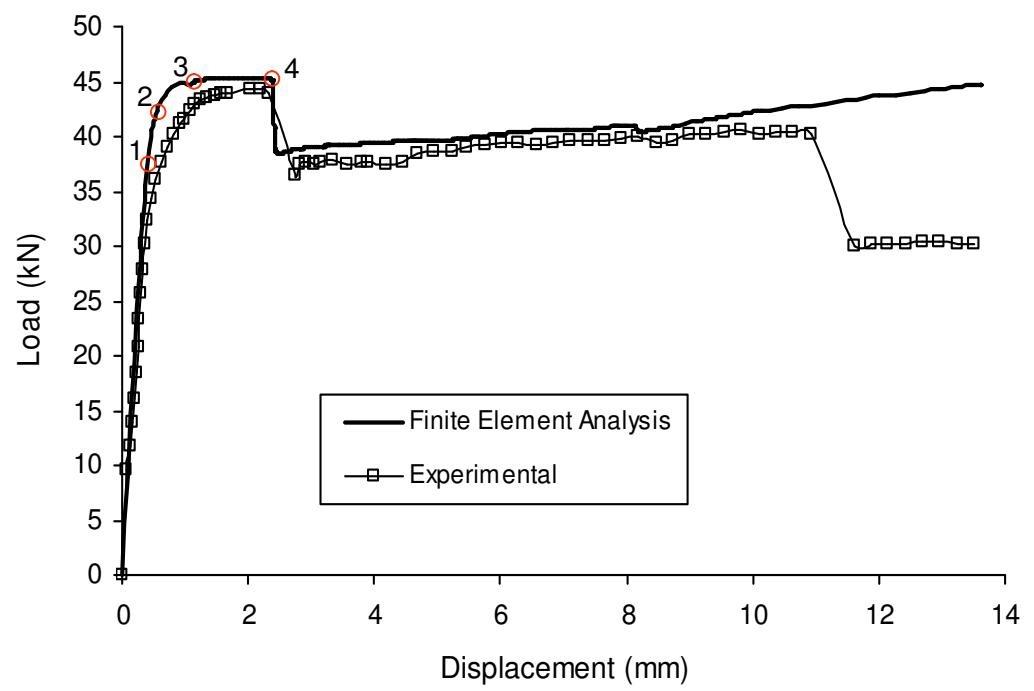

(a) 

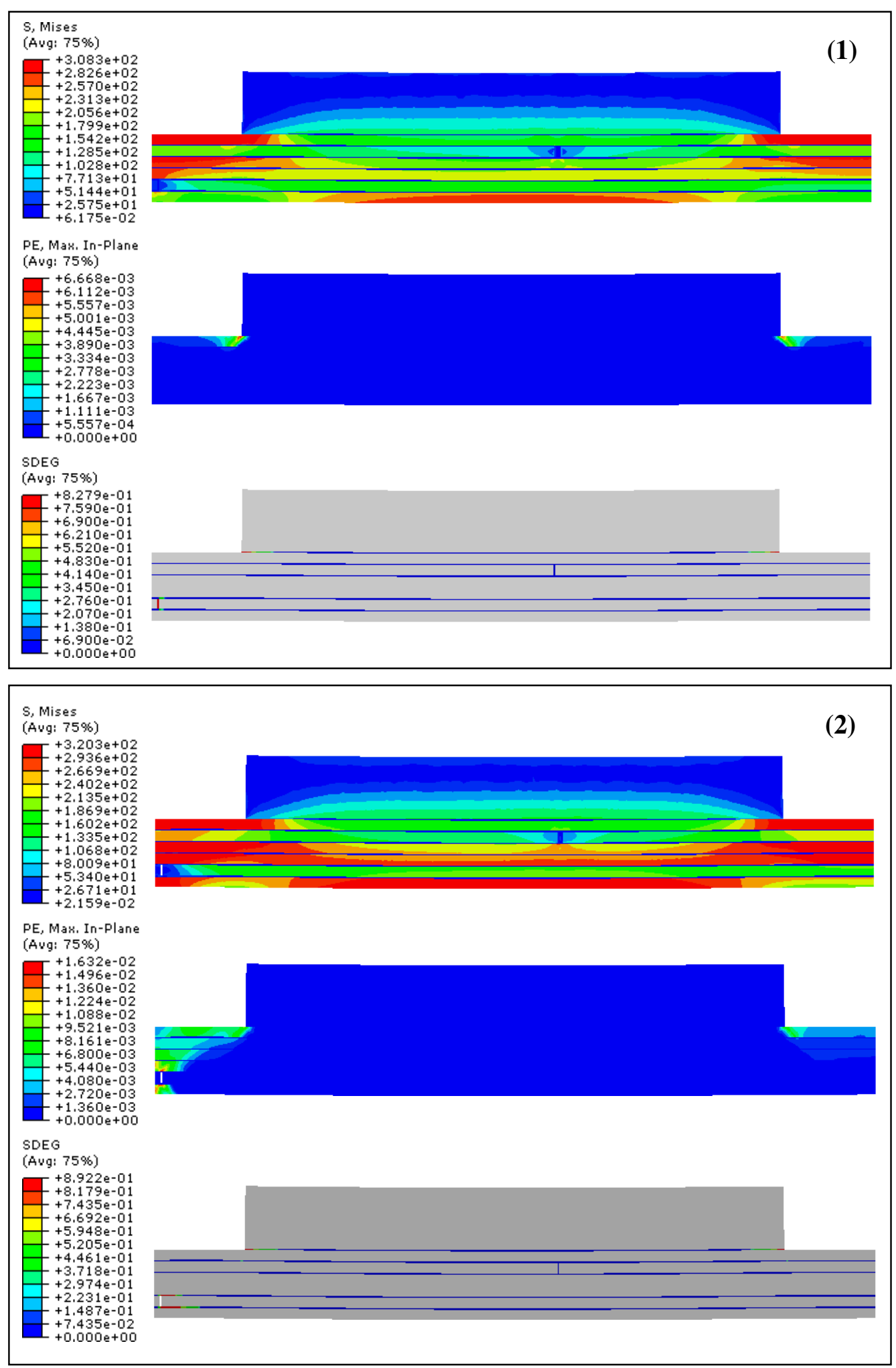

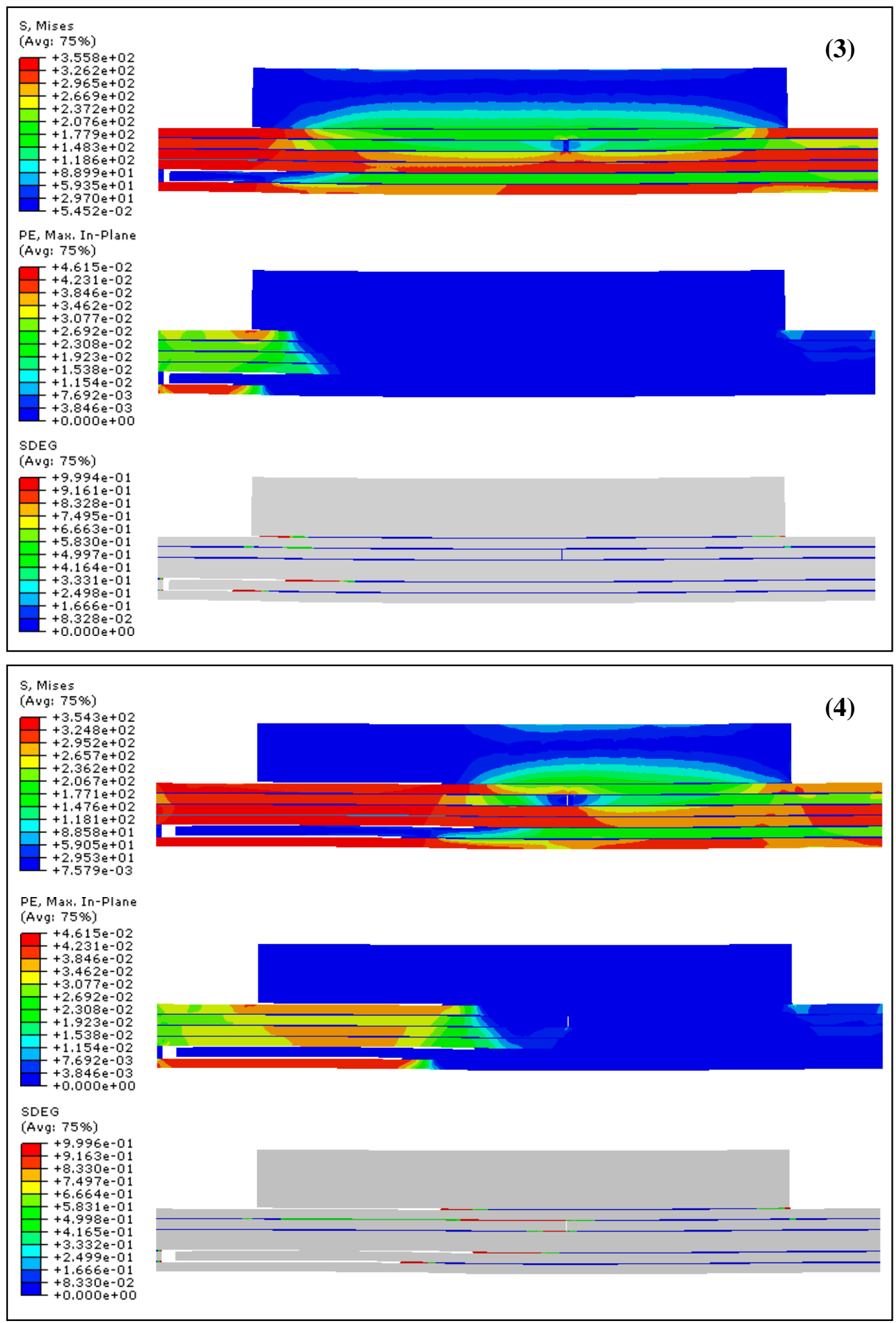

(b)

Fig. 13. (a) Load-displacement response of CH-B1 from FE modelling and experimental, (b) Modelling contour plot for CH-B1 (deformation scale factor is 1). 


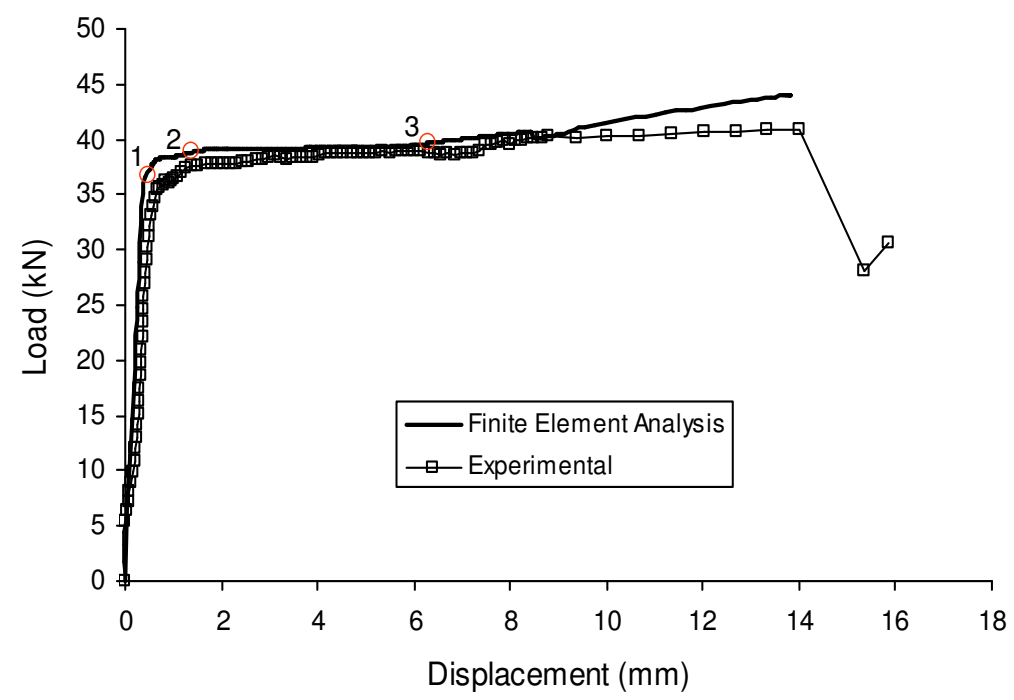

(a)

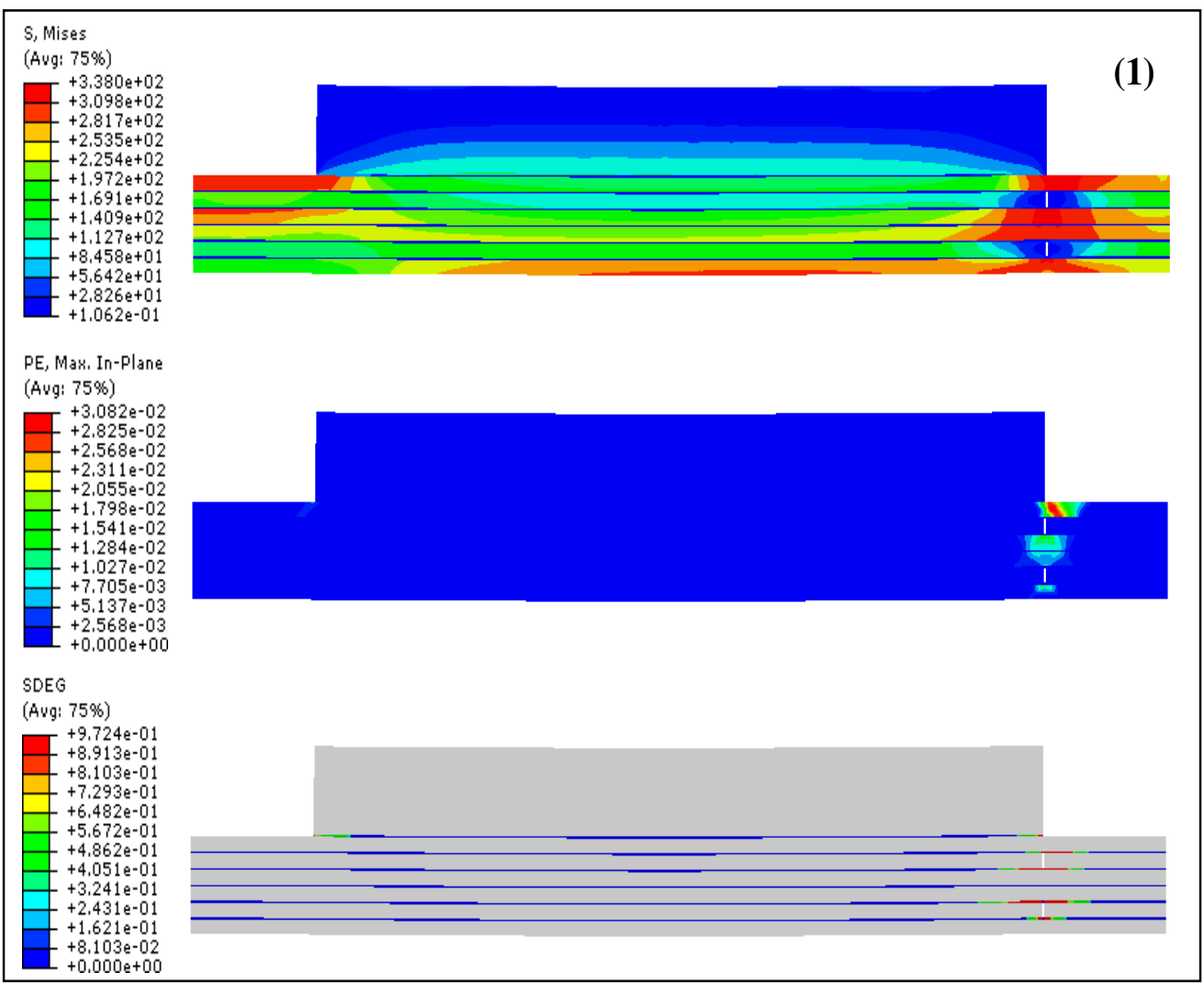



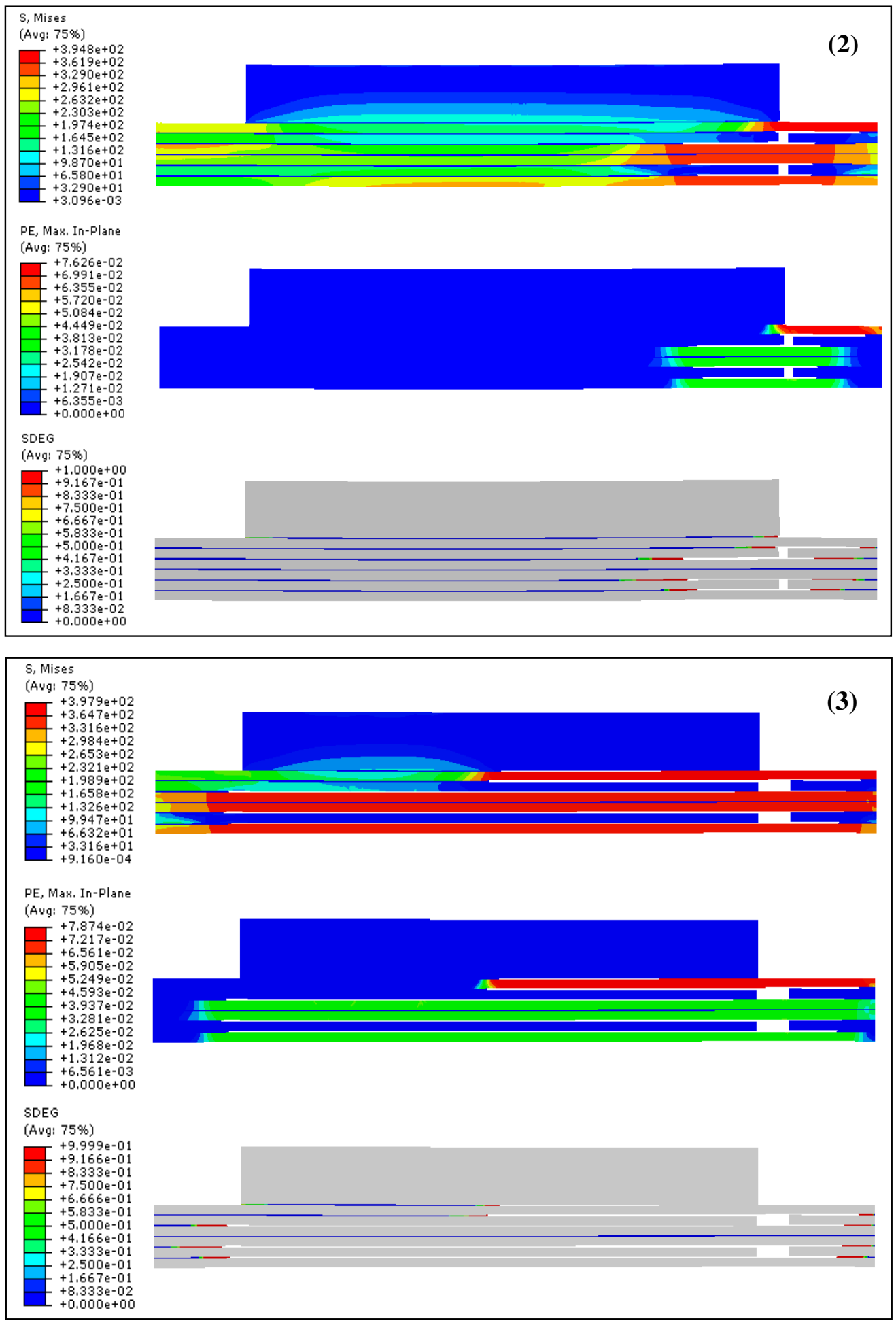

(b)

Fig. 14. (a) Load-displacement response of CH-B2 from FE modelling and experimental, (b) Modelling contour plot for $\mathrm{CH}-\mathrm{B} 2$ (deformation scale factor is 1). 


\section{LIST OF TABLE CAPTION}

Table 1. The average static strength of the hybrid FML joints

Table 2. The elastic properties Al 2024-T3 and adhesive FM 73M

Table 3. Plasticity data for Al 2024-T3 [17]

Table 4. Mechanical properties of gfrp [20]

Table 5. Cohesive zone properties

Table 6. The equivalent orthotropic properties of Glare [32]

Table 7. Plasticity data for Glare in the axial direction [7] 
Table 1. The average static strength of the hybrid FML joints

\begin{tabular}{lccc}
\hline \multirow{2}{*}{ Specimen } & \multicolumn{2}{c}{ Static strength $(\mathrm{kN})$} & Variation \\
\cline { 2 - 3 } & Experimental & Modelling & $(\%)$ \\
\hline SP & 82.45 & 83.22 & 0.9 \\
CH-NB & 57.78 & 58.82 & 1.8 \\
CH-B1 & 44.69 & 45.26 & 1.3 \\
CH-B2 & 41.25 & 40.90 & -0.8
\end{tabular}

Table 2. The elastic properties Al 2024-T3 and adhesive FM 73M

\begin{tabular}{lccc}
\hline Materials & $\begin{array}{c}\text { Young Modulus, } E \\
(\mathrm{MPa})\end{array}$ & Poisson's ratio, $v$ & $\begin{array}{c}\text { Shear modulus, } G \\
(\mathrm{MPa})\end{array}$ \\
\hline Al 2024-T3 & & & \\
- Longitudinal $^{\mathrm{a}}$ & 72,000 & 0.33 & 27,000 \\
- Transverse $_{\text {FM 73M }^{\mathrm{b}}}^{72,000}$ & 0.33 & 27,000 \\
\hline
\end{tabular}

${ }^{a}$ Reference [14]

${ }^{\mathrm{b}}$ Reference [16]

Table 3. Plasticity data for Al 2024-T3 [17]

\begin{tabular}{cccc}
\hline \multicolumn{2}{c}{ Longitudinal } & \multicolumn{2}{c}{ Transverse } \\
\hline $\begin{array}{c}\text { Yield stress } \\
(\mathrm{MPa})\end{array}$ & Plastic strain & $\begin{array}{c}\text { Yield stress } \\
(\mathrm{MPa})\end{array}$ & Plastic strain \\
\hline 300 & 0.000 & 290 & 0.000 \\
330 & 0.003 & 300 & 0.003 \\
370 & 0.015 & 340 & 0.011 \\
420 & 0.043 & 390 & 0.035 \\
440 & 0.100 & 430 & 0.100 \\
\hline
\end{tabular}


Table 4. Mechanical properties of gfrp [20]

\begin{tabular}{lcccccccc}
\hline \multicolumn{1}{c}{ Gfrp } & $\begin{array}{c}E \\
(\mathrm{GPa})\end{array}$ & $v$ & $\begin{array}{c}G \\
(\mathrm{GPa})\end{array}$ & $\begin{array}{c}G_{T} \\
(\mathrm{~N} / \mathrm{mm})\end{array}$ & $\begin{array}{c}G_{C} \\
(\mathrm{~N} / \mathrm{mm})\end{array}$ & $\begin{array}{c}\sigma_{T} \\
(\mathrm{MPa})\end{array}$ & $\begin{array}{c}\sigma_{C} \\
(\mathrm{MPa})\end{array}$ & $\begin{array}{c}T \\
(\mathrm{MPa})\end{array}$ \\
\hline Longitudinal & 50 & 0.33 & 3.5 & 12.5 & 12.5 & 1500 & 550 & 93 \\
Transverse & 9 & 0.04 & 3 & 1 & 1 & 43 & 90 & 50
\end{tabular}

$G_{T}=$ fracture energy in tension, $G_{C}=$ fracture energy in compressive

$\sigma_{T}=$ tensile strength,$\sigma_{C}=$ compressive strength,$T=$ shear strength

Table 5. Cohesive zone properties

\begin{tabular}{ccccccccc}
\hline Material & $\begin{array}{c}E \\
(\mathrm{GPa})\end{array}$ & $\begin{array}{c}G \\
(\mathrm{GPa})\end{array}$ & $\begin{array}{c}G_{I} \\
(\mathrm{~N} / \mathrm{mm})\end{array}$ & $\begin{array}{c}G_{I I} \\
(\mathrm{~N} / \mathrm{mm})\end{array}$ & $\begin{array}{c}G_{I I I} \\
(\mathrm{~N} / \mathrm{mm})\end{array}$ & $\begin{array}{c}T_{n} \\
(\mathrm{MPa})\end{array}$ & $\begin{array}{c}T_{t} \\
(\mathrm{MPa})\end{array}$ & $\begin{array}{c}T_{s} \\
(\mathrm{MPa})\end{array}$ \\
\hline Cohesive-1* & 2 & 0.75 & 2 & 4 & 4 & 65 & 38 & 38 \\
Cohesive-2 & 2 & 0.75 & 0.9 & 1.8 & 1.8 & 30 & 17 & 17 \\
\hline
\end{tabular}

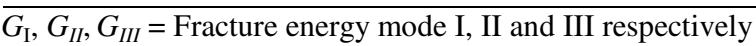

$T_{n}, T_{b}, T_{s}=$ Traction in tension, in shear 1 and in shear 2 respectively

* Reference [24]

Table 6. The equivalent orthotropic properties of Glare [32]

\begin{tabular}{ccccccccc}
\hline $\begin{array}{c}E_{1} \\
(\mathrm{GPa})\end{array}$ & $\begin{array}{c}E_{2} \\
(\mathrm{GPa})\end{array}$ & $\begin{array}{c}E_{3} \\
(\mathrm{GPa})\end{array}$ & $v_{12}$ & $v_{13}$ & $v_{23}$ & $\begin{array}{c}G_{12} \\
(\mathrm{GPa})\end{array}$ & $\begin{array}{c}G_{13} \\
(\mathrm{GPa})\end{array}$ & $\begin{array}{c}G_{23} \\
(\mathrm{GPa})\end{array}$ \\
\hline 60 & 45 & 22 & 0.33 & 0.33 & 0.24 & 8.5 & 8.5 & 7.5 \\
\hline
\end{tabular}

$E=$ Modulus Young, $v=$ Poison's ratio, $G=$ Shear modulus

Table 7. Plasticity data for Glare in the axial direction [7]

\begin{tabular}{lcccccc}
\hline $\begin{array}{l}\text { Yield stress } \\
(\mathrm{MPa})\end{array}$ & 200 & 225 & 250 & 275 & 300 & 325 \\
\hline \begin{tabular}{l} 
Plastic strain \\
\hline
\end{tabular} & 0 & 0.0025 & 0.005 & 0.0158 & 0.0258 & 0.0408 \\
\hline
\end{tabular}

